\title{
Mitochondrial metabolism directs stemness and differentiation in P19 embryonal carcinoma stem cells
}

\author{
I Vega-Naredo ${ }^{1}$, R Loureiro', KA Mesquita ${ }^{1,2}$, IA Barbosa ${ }^{1}$, LC Tavares ${ }^{1,2}$, AF Branco ${ }^{1}$, JR Erickson ${ }^{3}$, J Holy ${ }^{4}$, EL Perkins ${ }^{5}$, \\ RA Carvalho ${ }^{1,2}$ and PJ Oliveira ${ }^{*, 6}$
}

The relationship between mitochondrial metabolism and cell viability and differentiation in stem cells (SCs) remains poorly understood. In the present study, we compared mitochondrial physiology and metabolism between P19SCs before/after differentiation and present a unique fingerprint of the association between mitochondrial activity, cell differentiation and stemness. In comparison with their differentiated counterparts, pluripotency of P19SCs was correlated with a strong glycolytic profile and decreased mitochondrial biogenesis and complexity: round, low-polarized and inactive mitochondria with a closed permeability transition pore. This decreased mitochondrial capacity increased their resistance against dichloroacetate. Thus, stimulation of mitochondrial function by growing P19SCs in glutamine/pyruvate-containing medium reduced their glycolytic phenotype, induced loss of pluripotent potential, compromised differentiation and became P19SCs sensitive to dichloroacetate. Because of the central role of this type of SCs in teratocarcinoma development, our findings highlight the importance of mitochondrial metabolism in stemness, proliferation, differentiation and chemoresistance. In addition, the present work suggests the regulation of mitochondrial metabolism as a tool for inducing cell differentiation in stem line therapies.

Cell Death and Differentiation (2014) 21, 1560-1574; doi:10.1038/cdd.2014.66; published online 16 May 2014

Embryonal carcinoma cells, including the P19 cell line, are pluripotent cancer stem cells (CSCs) derived from pluripotent germ cell tumors called teratocarcinomas. These have been described as the malignant counterparts of embryonic stem cells (ESCs) and are considered a good model to study stem cell (SC) differentiation. The P19 cell line can be maintained as undifferentiated cells (P19SCs) or differentiated (P19dCs) to any cell type of the three germ layers. Similar to ESCs, P19 cells differentiate with retinoic acid (RA) in a dose-dependent manner and depending on growth conditions. ${ }^{1}$ Although differentiation generally yields a mixed population of differentiated cells, $\mathrm{P} 19$ cells grown in monolayer and treated with $1 \mu \mathrm{M}$ RA primarily differentiate in endoderm or mesoderm, while retaining their immortality. 2,3

Although some therapeutic approaches for regenerative medicine and to targeting CSCs are based on differentiation ${ }^{4}$ and mitochondrial-targeted therapies, ${ }^{5,6}$ very little is known about the role of mitochondrial metabolism in SC maintenance and differentiation. ${ }^{7}$ Several mitochondrial characteristics that distinguish transformed cells from healthy cells have been described, ${ }^{8}$ including increased mitochondrial transmembrane electric potential $(\Delta \psi \mathrm{m})$, which may result from decreased mitochondrial ATP production under normoxia. ${ }^{9}$ Similarly, normal SCs primarily rely on glycolysis for energy supply, although the exact mechanism how this occurs in the presence of oxygen and the relationship between SC metabolism and cell fate control is not yet completely understood. ${ }^{10}$

Given the mitochondrial involvement in stemness and differentiation, ${ }^{11}$ one can ask whether manipulation of mitochondrial physiology results in an improvement of therapy efficacy. Therefore, characterizing the metabolic and mitochondrial profiles of both SCs and differentiated cells holds promise in order to explain the resistance of cancer cells expressing an embryonic signature to mitochondrial-targeted therapies. In the present work, we have two tandem hypotheses: (a) metabolic and mitochondrial remodeling accompanies P19SC differentiation and (b) P19SC differentiation results in a higher susceptibility to mitochondrialdirected therapies.

${ }^{1}$ CNC-Center for Neuroscience and Cell Biology, University of Coimbra, 3004-517 Coimbra, Portugal; ${ }^{2}$ Department of Life Sciences, University of Coimbra, 3004-517 Coimbra, Portugal; ${ }^{3}$ Chicago Medical School, Rosalind Franklin University of Medicine and Science, North Chicago, IL 60064, USA; ${ }^{4}$ Department of Biomedical Sciences, University of Minnesota-Duluth, Duluth, MN 55812, USA; ${ }^{5}$ Department of Biomedical Sciences, Mercer University School of Medicine, Savannah, GA 31404 , USA and ${ }^{6} \mathrm{CNC}$-Center for Neuroscience and Cell Biology, University of Coimbra, UC Biotech Building, Lot 8A, Biocant Park, 3060-197 Cantanhede, Portugal ${ }^{*}$ Corresponding author: PJ Oliveira, CNC-Center for Neuroscience and Cell Biology, University of Coimbra, UC Biotech Building, Lot 8A, Biocant Park, 3060-197 Cantanhede, Portugal. Tel: +3513 0450 2911; Fax: +3512 3985 3409; E-mail: pauloliv@ ci.uc.pt

Abbreviations: ANT, adenine nucleotide translocase; ADP, adenosine diphosphate; ATP5A, ATP synthase subunit $\alpha$; COX IV, cytochrome c oxidase subunit IV; CSCs, cancer stem cells; CyP-D, cyclophilin D; ESCs, embryonic stem cells; ETC, electron transport chain; FCCP, carbonyl cyanide 4-(trifluoromethoxy)phenylhydrazone; HBSS, Hank's Balanced Salt Solution; mPTP, mitochondrial permeability transition pore; MTCO1, cytochrome $c$ oxidase subunit I; mTFA, mitochondrial transcription factor A; MTG, MitoTracker Green; MTR, MitoTracker Red; NANOG, nanog homeobox protein; NDUFB8, NADH dehydrogenase (ubiquinone) $1 \beta$ subcomplex 8; NMR, nuclear magnetic resonance; OCT4, octamer-binding transcription factor; OXPHOS, oxidative phosphorylation; P19dC, differentiated P19 cell; P19SC, P19 stem cell; PDH, pyruvate dehydrogenase; PDK, pyruvate dehydrogenase kinase; PGC-1, peroxisomal proliferator-activated receptor coactivator 1; PI, propidium iodide; RA, retinoic acid; ROS, reactive oxygen species; SCs, stem cells; SDHB, succinate dehydrogenase (ubiquinone) iron-sulfur subunit; SOX2, sex determining region Y-box 2; TMRM, tetramethylrhodamine methyl ester; TOM20, translocase of outer mitochondrial membrane 20; TROMA-1, cytokeratin 8 Endo-A; UQCRC2, ubiquinol-cytochrome $\mathrm{c}$ reductase core protein $\mathrm{Il} \Delta \mathrm{\psi} \psi \mathrm{m}$, mitochondrial transmembrane electric potential

Received 18.9.13; revised 28.2.14; accepted 07.4.14; Edited by L Scorrano; published online 16.5.14 


\section{Results}

Differentiation of P19SCs led to loss of pluripotency and mitochondrial remodeling. Undifferentiated P19SCs exhibited high nucleus-to-cytoplasm ratio and reduced trophectodermal cytokeratin 8 Endo-A (TROMA-1) expression (Figure 1a). Upon the addition of $1 \mu \mathrm{M}$ RA for 4 days, P19 cells expressed markers of differentiation, including TROMA-1, Musashi and $\beta$ III-tubulin. At the same time, loss of pluripotency markers octamer-binding transcription factor (OCT4), nanog homeobox protein (NANOG) and sex determining region Y-box 2 (SOX2) occurred (Figure 1b). Differentiation was also characterized by the appearance of more lobular and euchromatic nuclei, cell flattening and alterations in microfilament organization (Figure 1a and Supplementary Figure s1). Interestingly, cell differentiation was accompanied by mitochondrial remodeling. Although the number of mitochondrial bodies detected by electron microscopy showed no obvious differences in both P19 cell populations (Figure 1c), there were evidences that mitochondria in P19dCs displayed higher elongation and interconnectivity, confirmed by staining with MitoTracker Red (MTR; Figure 1d). In this regard, we questioned whether mitochondrial elongation would also occur during differentiation in a three-dimensional (3D) culture system. Labeling spheroids with tetramethylrhodamine methyl ester (TMRM) and calcein-AM showed that spheres formed from P19SCs had small and round mitochondria, whereas P19dCs exhibited filamentous mitochondria (Figure 1d). To explore the possibility of differences in dye extrusion, cells were pre-treated with $100 \mu \mathrm{M}$ verapamil for $20 \mathrm{~min}$ before loading with fluorescent molecules showing no effects on the amount of dye uptake for either cell line (Supplementary Figure s2).

To further examine mitochondrial differentiation after RA treatment, markers for mitochondrial mass and biogenesis were investigated. Peroxisomal proliferator-activated receptor coactivator 1 (PGC-1) presented a decreased protein expression a
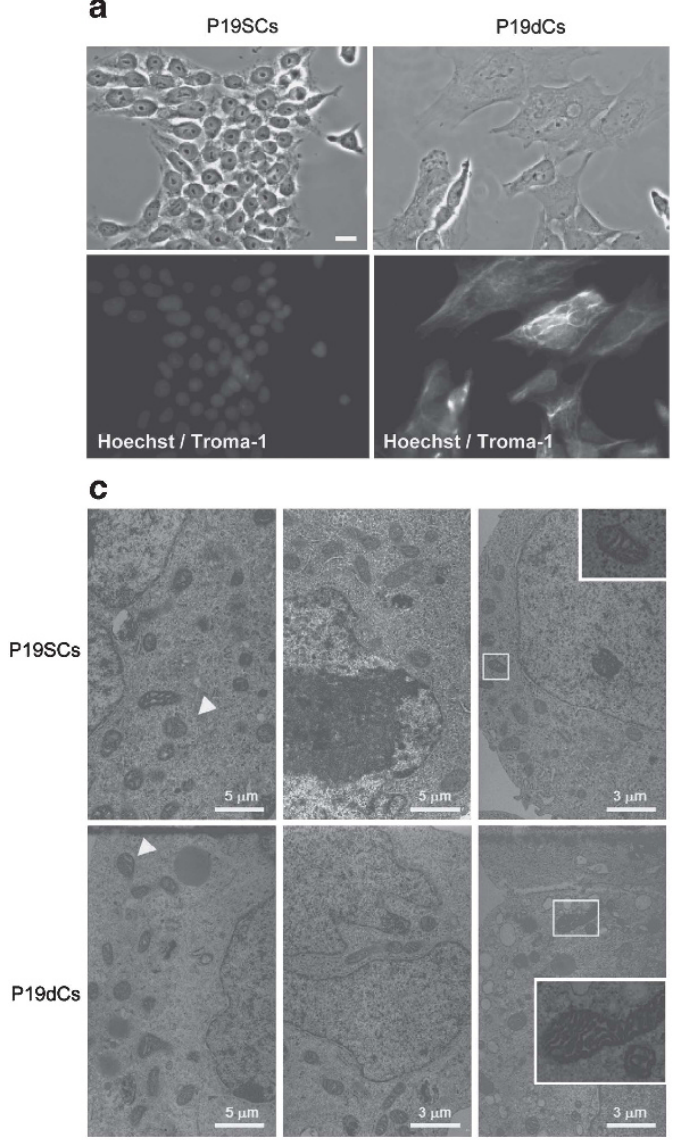

b
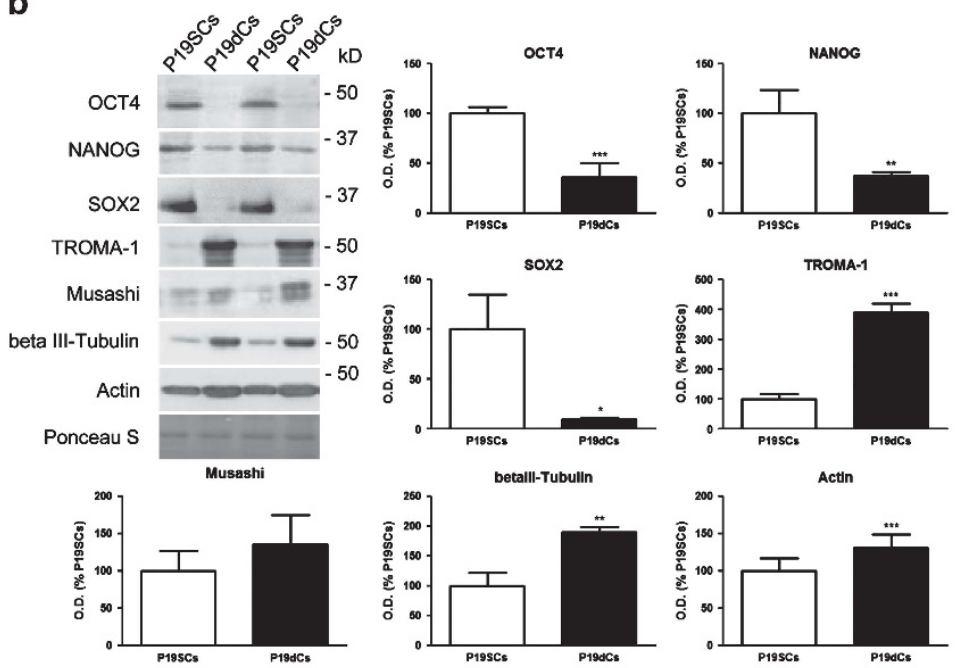

d
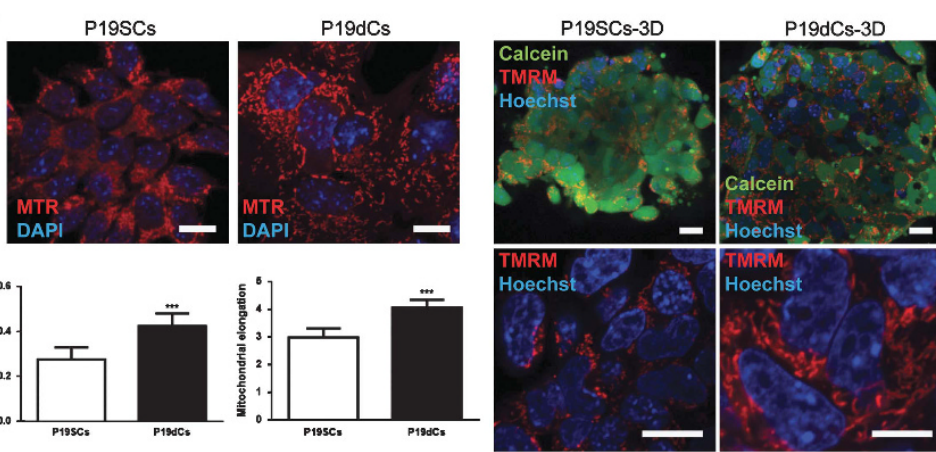

Figure 1 Retinoic acid induces cell differentiation and alterations in mitochondrial morphology in P19SCs. (a) Phase contrast images of P19SCs and P19dCs. Immunostaining of P19 cells confirms the expression of TROMA-1 only in P19dCs. Scale bar $=10 \mu \mathrm{m}$. (b) Pluripotency (OCT4, NANOG and SOX2) and differentiation (TROMA-1, Musashi and $\beta$ III-tubulin) markers in P19SCs and P19dCs. Bar charts show means of optical density (O.D.) \pm S.D. expressed as percentage of P19SCs, from at least three separate immunoblots. ${ }^{\star} P<0.05 ;{ }^{* \star} P<0.01 ;{ }^{* \star} P<0.001$. (c) Electron microscopy photographs of $P 19$ cells show round mitochondria, which are similar in P19SCs and P19dCs (arrows) in nearly equal amounts. Pictures show representative fields of over 50 cells photographed. (d) Confocal images obtained using MitoTracker Red (MTR) or TMRM for mitochondrial labeling and DAPI or Hoechst for nuclear labeling show alterations in mitochondrial morphology between P19SCs and P19dCs, growing in monolayer and in spheroids (3D). Some spheroids were stained with calcein-AM for cell viability determination. Scale bar $=15 \mu \mathrm{m}$. Bar charts show mitochondrial interconnectivity and mitochondrial elongation measured using Image $J$ in fluorescent images of P19SCs and P19dCs grown in monolayer and stained with MitoTracker. Data show mean \pm S.D. ${ }^{* * *} P<0.001 ; n=15$ cells, three separate experiments 
after differentiation (Figure 2a). However, its mRNA levels (Ppargc1a) remained unchanged, although a longer treatment time with RA (8 days) significantly increased Ppargc1a (Supplementary Figure s3). On the other hand, a marked difference between both groups regarding the mitochondrial transcription factor A (mTFA) was observed. The immunoblot against mTFA showed a single band corresponding to $29 \mathrm{kDa}$ in P19SCs and two bands at 29 and $25 \mathrm{kDa}$ in P19dCs. By isolating mitochondrial and cytoplasmic extracts (Figure $2 b$ ), we demonstrated that the 29-kDa band corresponds to the cytoplasmic precursor of mTFA, which is thereafter processed to $25 \mathrm{kDa}$ when imported to mitochondria. ${ }^{12}$ Thus, mitochondrial biogenesis is apparent in P19dCs. Notwithstanding, no differences in cytochrome $c$ oxidase subunit IV (COX IV), translocase of outer mitochondrial membrane 20 (TOM20; Figure 2a) and mtDNA copy number (Figure 2c) were observed. Collectively, this indicates that P19SCs and P19dCs have similar amounts of mitochondria, although with distinct structural and possibly functional features.

To assess whether mTFA is indispensable for cell differentiation, we silenced MTFA by using an siRNA technique and treated cells with RA after confirming mTFA depletion $48 \mathrm{~h}$ after transfection (Figure $2 \mathrm{~d}$ ). We found that P19 mTFA-silenced cells treated with RA (si-mTFA P19dCs) showed a lower expression of the differentiation markers TROMA-1 and $\beta$ III-tubulin when compared with non-silenced P19dCs. Thus, mitochondrial biogenesis seems to be necessary to induce the differentiation pathway. In addition, after the 4 days of treatment, si-mTFA P19dCs showed increased mTFA expression, resulting probably from an attempt to overcome the hindrance in mitochondrial biogenesis activation resulting from the transient mTFA silencing (Figure 2e).

Differentiation of P19SCs stimulated mitochondrial function. Immunocytochemistry against the mitochondrial marker TOM20 and using MTR to stain polarized mitochondria showed that while P19dCs contained the majority of the mitochondrial network in a polarized state, colonies formed by P19SCs presented a core of cells with low-polarized mitochondria (Figure 3a). This was supported by labeling mitochondria with TMRM. P19SCs showed few, small and round polarized bodies, whereas P19dCs displayed long polarized mitochondrial filaments (Figure 3b). Likewise,

a
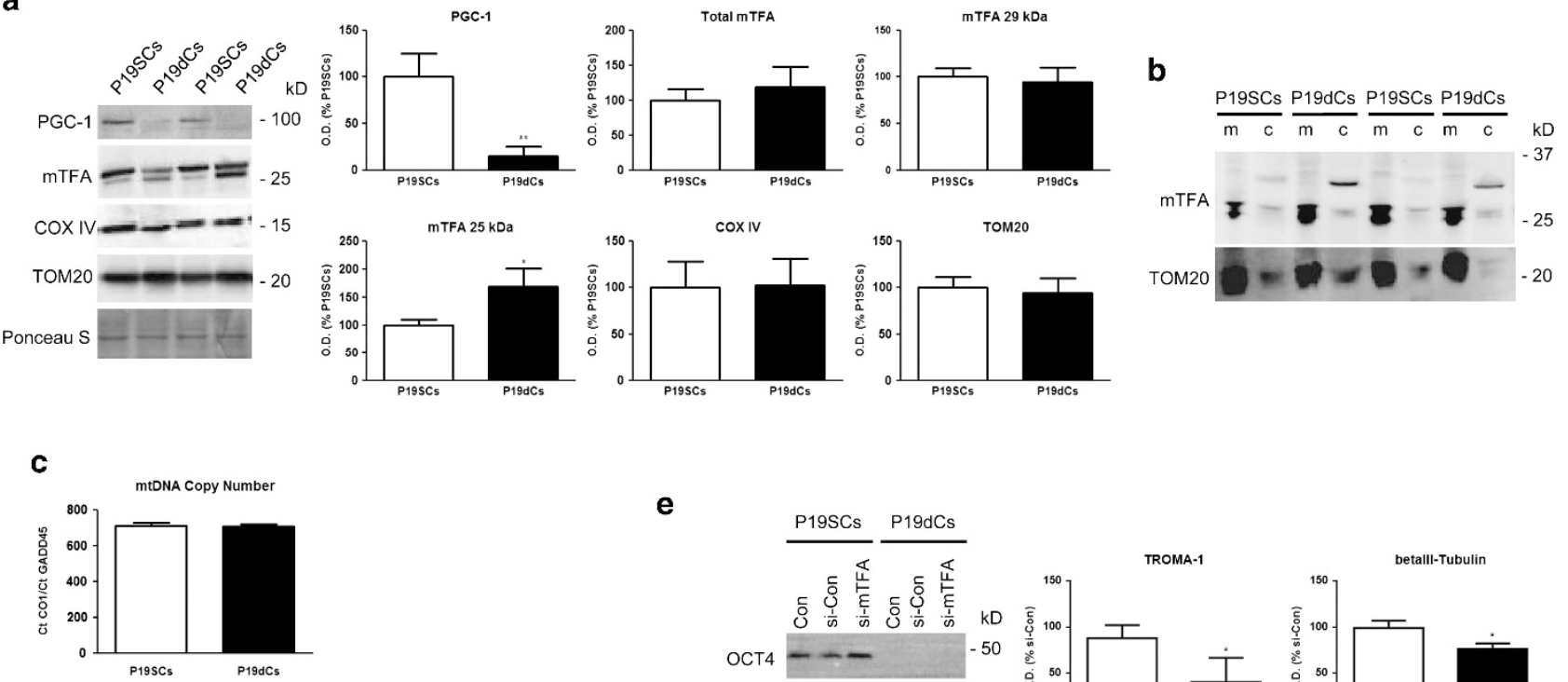

d
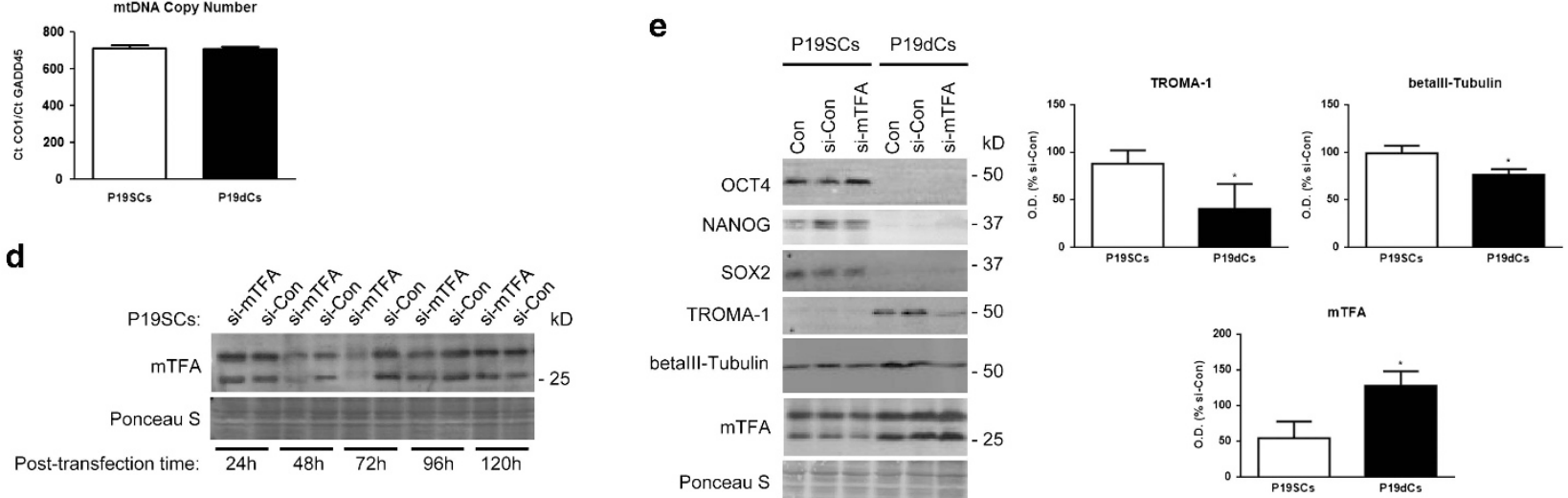

Figure 2 Mitochondrial differentiation accompanies cell differentiation in P19 cells treated with RA. (a) Levels of proteins involved in mitochondrial biogenesis (PGC-1 and mTFA) confirm the differentiation of mitochondria during P19SCs to P19dCs transition. TOM20 and COX IV amounts suggest similar mitochondrial content. Bar charts show means of optical density (O.D.) \pm S.D. expressed as percentage of P19SCs, from at least three separate immunoblots. ${ }^{*} P<0.05$; ${ }^{* *} P<0.01$. (b) Localization of mTFA in mitochondrial $(\mathrm{m})$ and cytosolic $(\mathrm{c})$ extracts confirms the presence of its mature form $(25 \mathrm{kDa})$ in mitochondrial extracts. TOM20 was used to check the purity of the mitochondrial fraction. (c) Relative mtDNA copy number determined by quantitative PCR using the mitochondrial CO1 gene and the nuclear GADD45 gene. Data are means \pm S.D. of three independent experiments. (d) Representative immunoblot for detecting mTFA expression overtime after transfection of P19SCs with either mTFA siRNA oligonucleotide (si-mTFA) or with a scrambled siRNA (si-Con). (e) Protein markers of pluripotency (OCT4, NANOG and SOX2) and differentiation (TROMA-1 and $\beta$ III-tubulin) markers in P19SCs, P19dCs and their transfected counterparts, si-mTFA and si-Con. Bar charts show means of optical density (O.D.) \pm S.D. expressed as percentage of their respective si-Con, from at least three separate immunoblots. Ponceau $\mathrm{S}$ was used for loading control. Statistical comparisons: ${ }^{*} P<0.05$ 
a

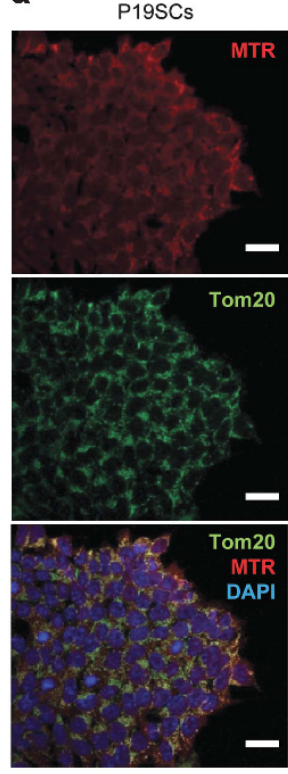

c

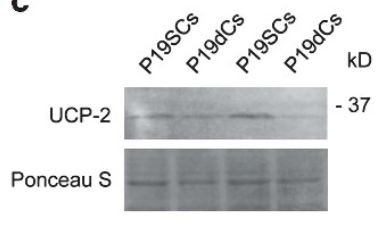

b
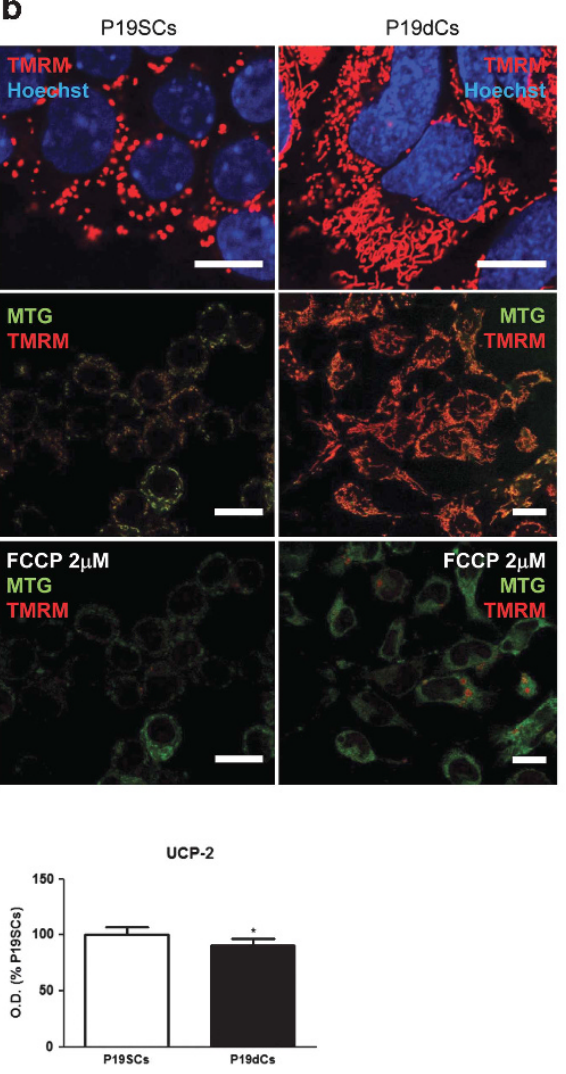

d
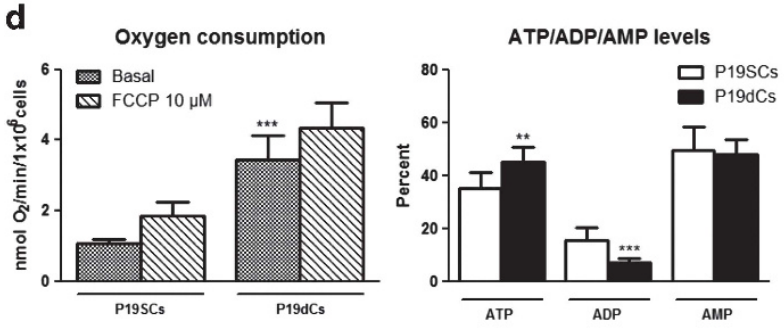

ATP levels

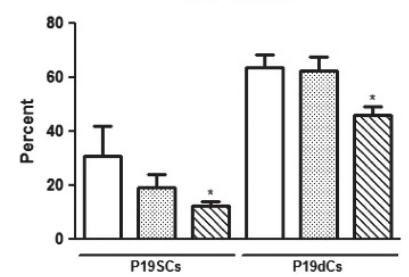

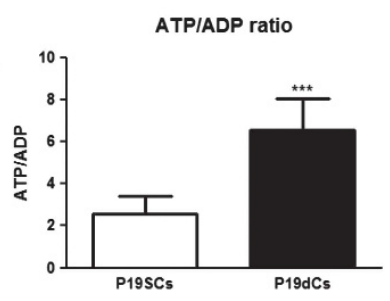

$\square$ Control

Oligomycin $1.3 \mu \mathrm{g} / \mathrm{ml}$ 2-DG $100 \mathrm{mM}$

Figure 3 Mitochondria from P19 cells became more polarized and functional after cell differentiation with RA. (a) Confocal images of P19SCs and P19dCs labeled with TOM20 and MitoTracker Red (MTR). Mitochondria from P19SCs are stained with the mitochondrial marker TOM20 but they do not load MTR. DAPI labels nuclei. Scale bar $=15 \mu \mathrm{m}$. (b) Confocal images obtained with the potentiometric dye TMRM show evident changes in mitochondrial structure and membrane potential after differentiation of P19SCs. Pictures from P19 cells co-loaded with TMRM and MitoTracker Green (MTG) before and after depolarizing with FCCP $(2 \mu \mathrm{M})$ confirm that mitochondria in P19SCs show little after the addition of FCCP. Scale bar $=15 \mu \mathrm{m}$. (c) Protein levels of uncoupling protein 2 (UCP-2) are higher in P19SCs. Bar charts show means of optical density (O.D.) \pm S.D. $(n=7)$ expressed as percentage of P19SCs. ${ }^{*} P<0.05$. (d) Basal oxygen consumption displayed as nmol of $\mathrm{O}_{2}$ per minute and per $10^{6}$ cells is higher in $\mathrm{P} 19 \mathrm{dCs}$ than in P19SCs. Ten $\mu$ M FCCP was added to test maximal respiration. ATP, ADP and AMP measurements taken by HPLC indicate an elevated ATP production and ATP/ADP ratio in P19dCs. Percentage of ATP levels in cells treated with $1.3 \mu \mathrm{g} / \mathrm{ml}$ oligomycin or $100 \mathrm{mM}$ 2-deoxyglucose (2-DG) for $3 \mathrm{~h}$ shows that ATP production is only sensitive to 2-DG in both types of P19 cells. Data are means \pm S.D. for $n=6$ experiments. ${ }^{*} P<0.05 ;{ }^{* \star} P<0.01 ;{ }^{* \star *} P<0.001$

co-loading assay with MitoTracker Green (MTG) and TMRM showed a higher TMRM fluorescence and MTG quenching for P19dCs (Figure 3b). The assay was repeated using flow cytometry demonstrating that although both types of P19 cells have similar amounts of MTG-labeled mitochondria, differentiation of P19 cells results in increased $\Delta \psi \mathrm{m}$ (Supplementary Figure s4). Accordingly, the expression of uncoupling protein 2 , a protein which is suggested to have a 
role in proton gradient dissipation and uncouple respiration from oxidative phosphorylation (OXPHOS), ${ }^{13}$ was higher in P19SCs (Figure 3c).

The comparative analysis of basal oxygen consumption showed a higher respiration rate in P19dCs. The addition of $2 \mu \mathrm{M}$ carbonyl cyanide 4-(trifluoromethoxy)phenylhydrazone (FCCP) was not able to increase oxygen consumption and only $10 \mu \mathrm{M}$ FCCP resulted in increased respiration in both groups, higher in P19dCs but without reaching statistical significance. Accordingly, P19dCs had significantly higher ATP content and ATP/ADP ratio than P19SCs. In order to dissect the relative contribution of glycolysis and OXPHOS, we measured ATP levels after treating P19SCs and P19dCs for $3 \mathrm{~h}$ with $1.3 \mu \mathrm{g} / \mathrm{ml}$ oligomycin to block OXPHOS or with $100 \mathrm{mM}$ 2-deoxyglucose to inhibit glycolysis. ATP levels decreased only when cells were treated with 2-deoxyglucose, indicating that both types of P19 cells rely primarily on glycolysis rather than OXPHOS for ATP production (Figure 3d). From all these data, we conclude that P19dCs have more functional mitochondria, although glycolysis is still a primary pathway from which ATP is obtained.
Differentiation of P19SCs alters the amount of components of the mitochondrial electron transport chain (ETC) and the open/closed state of the permeability transition pore. Based on the above data, we hypothesized that OXPHOS machinery was remodeled during RA-inducing differentiation. We compared the expression of subunits of the mitochondrial ETC complexes, namely NADH dehydrogenase (ubiquinone) $1 \beta$ subcomplex 8 (NDUFB8) from complex I; succinate dehydrogenase (ubiquinone) iron-sulfur subunit (SDHB) from complex II; ubiquinol-cytochrome $c$ reductase core protein II (UQCRC2) from complex III; cytochrome $c$ oxidase subunit I (MTCO1) from complex IV and ATP synthase subunit $\alpha$ (ATP5A) from complex $V$ by immunodetection. No significant differences in the content of subunits from complexes II, IV and V were found. However, NDUFB8 and UQCRC2 showed a reduced content in P19dCs (Figure 4a), suggesting that P19SCs differentiation decreased the content of subunits from complexes where superoxide anion is formed. Still, MitoSOX fluorescence revealed higher mitochondrial superoxide anion in $\mathrm{P} 19 \mathrm{dCs}$ providing further evidence of ETC remodeling during a
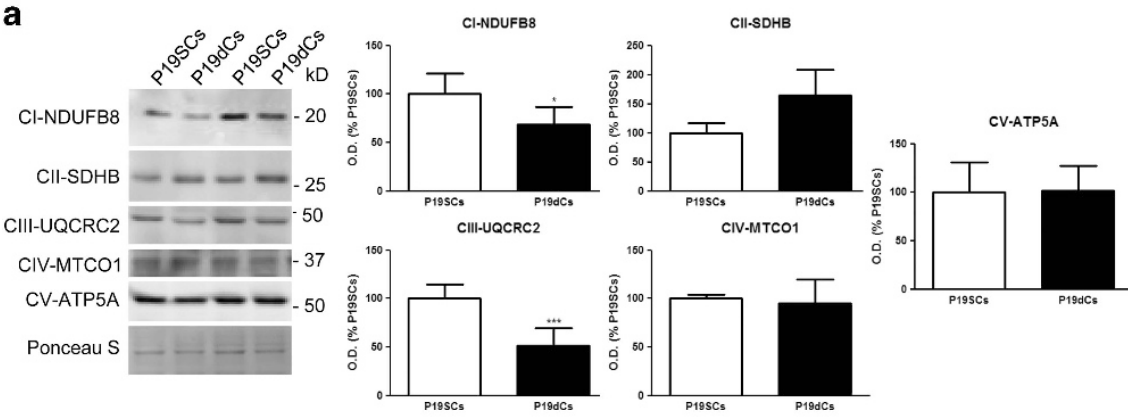

b

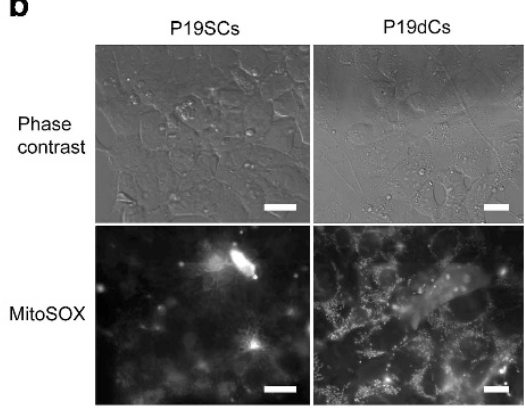

C

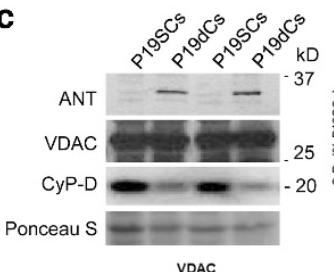
VDAC

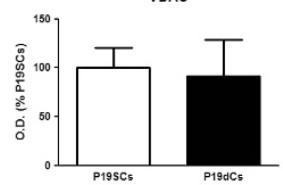

ANT
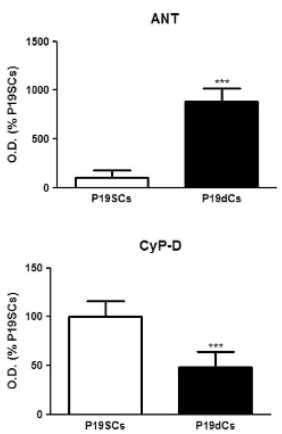

d

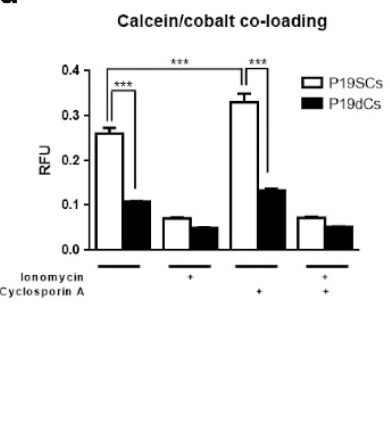

e
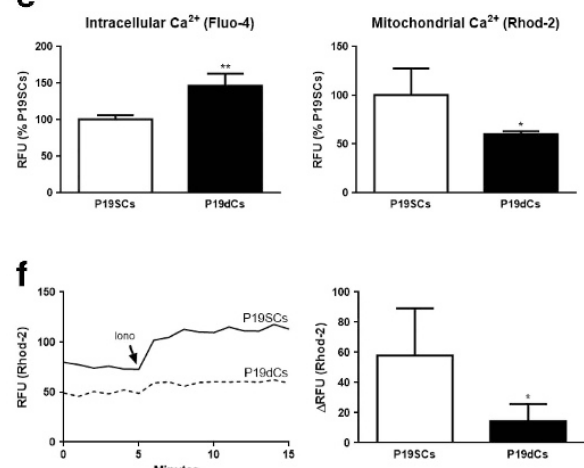

Figure 4 Differentiation of P19SC remodels constituents of mitochondrial OXPHOS apparatus and mitochondrial permeability transition pore (mPTP). (a) OXPHOS subunits from the five complexes (NDUFB8, SDHB, UQCRC2, MTC01 and ATP5A) were analyzed in P19SCs and P19dCs. Ponceau S was used for loading control. Bar charts show means of optical density (O.D.) \pm S.D. expressed as percentage of P19SCs, from at least three separate experiments. ${ }^{*} P<0.05$. (b) Images of MitoSOX fluorescence in P19SCs and P19dCs show a dramatic increase in mitochondrial superoxide anion production in P19dCs. Scale bar $=15 \mu \mathrm{m}$. (c) Adenine nucleotide translocator (ANT), voltage-dependent anion channel (VDAC) and cyclophilin D (CyP-D) protein content show significant changes between P19SCs and P19dCs. Ponceau S was used for loading control and histograms show means of optical density (O.D.) \pm S.D. expressed as percentage of P19SCs, from three separate experiments. ${ }^{* * \star} P<0.001$. (d) Flow cytometric measurement of cobalt quenching of calcein fluorescence as an end point for mPTP opening reveal a more closed conformation in P19SCs than in P19dCs. Cyclosporin $\mathrm{A}(2 \mu \mathrm{M})$ is able to inhibit pore opening only in P19SCs. Ionomycin $(0.5 \mu \mathrm{M})$ was used to induce pore opening. Data are shown as relative fluorescence units (RFUs) that represent the mean average of geometric mean values \pm S.D., normalized to fluorescence of cells incubated with calcein only for $n=3$. ${ }^{* * *} P<0.001$. (e) Intracellular (detected by Fluo-4 fluorescence) and mitochondrial (detected by Rhod-2 fluorescence) measurement of $\mathrm{Ca}^{2+}$ levels reveals a higher concentration of intracellular free $\mathrm{Ca}^{2+}$ in P19dCs. Data are means \pm S.D. from at least three separate experiments. ${ }^{*} P<0.05,{ }^{* *} P<0.01$. (f) To evaluate $\mathrm{Ca}^{2+}$ retention capacity of mitochondria, P19 cells loaded with Rhod-2 were stimulated at minute 5 with $10 \mu \mathrm{M}$ ionomycin (lono) followed by the fluorescence assessment of the Rhod-2 signal over time. Representative traces and quantitative data illustrating the $\triangle \mathrm{RFU}$ (minute 15-minute 5) are shown. Data are means \pm S.D., $n=5 .{ }^{*} P<0.05$ 
P19SCs differentiation (Figure 4b). As there is emerging evidence that reactive oxygen species (ROS) are required for differentiation, P19 cells were differentiated in the presence of $1 \mathrm{mM} \mathrm{N}$-acetylcysteine showing higher expression of the trophoectodermal marker TROMA-1 and evident morphological alterations (Supplementary Figure s5). Consequently, the presence of the antioxidant during the differentiation process, although not completely inhibiting differentiation, appears to limit its extension and direction, retaining P19 cells in a trophoectodermal stage.

P19SCs differentiation also led to an increased content of adenine nucleotide translocase (ANT), but not voltagedependent anion channel (VDAC; Figure 4c). On the other hand, time-drive quantitative measurement of their transcripts revealed evident changes during differentiation (Ant-1, Ant-2 and Vdac-3, Supplementary Figure s3).

The stabilization of the mitochondrial permeability transition pore (mPTP), regulated by cyclophilin D (CyP-D),${ }^{14}$ is critical for mitochondrial function. We observed a reduced content of CyP-D in P19dCs (Figure 4c). To assess whether mPTP opening is altered during differentiation, we used the calcein/ cobalt method. The cobalt quenching of calcein fluorescence, used as an end point for mPTP opening, was $80.7 \%$ in P19SCs and $89.4 \%$ in P19dCs. Indeed, the mitochondrial calcein loading showed $58 \%$ lower in P19dCs versus $\mathrm{P} 19 \mathrm{SCs}$, if attending to the fluorescent values. Cyclosporin A, a pore desensitizer, decreased cobalt quenching only in P19SCs, increasing mitochondrial calcein fluorescence by about $27 \%$. The increased content CyP-D in P19SCs could be the explanation for the ability of cyclosporin $A$ to close basal mPTP only in P19SCs. Nonetheless, cyclosporin A was not efficient when mPTP opening was triggered with $0.5 \mu \mathrm{M}$ ionomycin (Figure 4d). To estimate if these results can be due to differences in calcium levels, we measured intracellular and mitochondrial free calcium concentrations using Fluo-4 and Rhod-2, respectively. P19dCs presented higher intracellular calcium levels, whereas, interestingly, P19SCs displayed higher mitochondrial levels (Figure 4e). Both types of P19 cells loaded with Rhod-2 were stimulated with $10 \mu \mathrm{M}$ ionomycin, as $0.5 \mu \mathrm{M}$ ionomycin did not result in differences in Rhod-2 fluorescence, to evaluate calcium retention ability of mitochondria. The results showed a higher calcium storage capacity for mitochondria from P19SCs (Figure 4f).

A higher expression of CyP-D has also been observed in several cancer cells as an apoptosis-suppressing mechanism $^{15}$ and accordingly, live/dead assay with calcein-AM and propidium iodide (PI) showed a higher percentage of dead cells (calcein-/PI + ) in P19dCs (Supplementary Figure s6).

These data indicate that differentiation of P19SCs modifies constituents of mitochondrial OXPHOS apparatus increasing its function, as well as constituents of $\mathrm{MPTP}$, resulting in a more open conformation.

P19SCs exhibit a strong glycolytic profile. Metabolic analysis was performed by ${ }^{1} \mathrm{H}$ - and ${ }^{13} \mathrm{C}$-nuclear magnetic resonance (NMR) analysis. Figures $5 \mathrm{a}$ and $\mathrm{b}$ show the timedrive of $\left[3-{ }^{13} \mathrm{C}\right]$ lactate and $\left[1-{ }^{13} \mathrm{C}\right]$ glucose ${ }^{1} \mathrm{H}-\mathrm{NMR}$ resonances, respectively. A graphical representation of $\left[3-{ }^{13} \mathrm{C}\right]$ lactate (Figure $5 \mathrm{c}$ ) and $\left[1-{ }^{13} \mathrm{C}\right]$ glucose (Figure $5 \mathrm{~d}$ ) shows clearly higher glycolytic flux in P19SCs than in
P19dCs. The ${ }^{1} \mathrm{H}$ - and ${ }^{13} \mathrm{C}-\mathrm{NMR}$ spectra of P19SCs and P19dCs extracts are presented in Figures $5 \mathrm{e}$ and $\mathrm{f}$, respectively. Overall, the levels of metabolic intermediates (e.g., glutamate, glutamine) were lower in P19SCs. Krebs cycle activity was very small in P19SCs, with reduced ${ }^{13} \mathrm{C}$ incorporation in glutamate; in contrast, in P19dCs there is significant incorporation of ${ }^{13} \mathrm{C}$, demonstrated by the appearance of a doublet in glutamate C3 (D34) and C4 multiplets (D34). This, together with the higher ratio $\mathrm{C} 3 / \mathrm{C} 4$, demonstrates a much more active oxidative metabolism in P19dCs.

In addition, we found an association of the glycolytic enzyme hexokinase-II to mitochondrial fractions in P19SCs being dramatically reduced after differentiation (Figure $5 \mathrm{~g}$ ). Together, our results demonstrate that although P19dCs are still glycolytic, P19SCs show a stronger glycolytic phenotype.

P19SCs lost pluripotency when mitochondrial ATP production was forced. P19SCs grown in OXPHOS medium (Gal-P19SCs), which forced ATP production by OXPHOS, ${ }^{16}$ showed higher $\Delta \psi \mathrm{m}$ and oxygen consumption than those grown in glucose medium (Glu-P19SCs). In addition, P19 cells in OXPHOS medium and treated with RA to try to trigger differentiation (Gal-P19dCs) showed the highest $\Delta \psi \mathrm{m}$ and oxygen consumption. Even so, Gal$\mathrm{P} 19 \mathrm{dCs}$ reached a higher respiration rate than Glu-P19dCs maintaining similar $\Delta \psi \mathrm{m}$ (Figure 6a). Moreover, co-localization of the mitochondrial marker TOM20 with MTR was higher in Gal-P19SCs than Glu-P19SCs, suggesting that a higher degree of polarization (Supplementary Figure s7a).

The sulforhodamine B (SRB) assay was used to evaluate whether cell proliferation was affected by forcing cells to acquire an oxidative metabolism. The results showed that P19dCs slowed their growth rate with respect to their stem counterparts. Proliferation of Gal-P19SCs was also reduced reaching values close to Glu-P19dCs. Gal-P19dCs exhibited the most reduced proliferation rate (Figure $6 b$ ).

Immunocytochemical detection of NANOG and MTR revealed an absence of NANOG in P19dCs. Only P19SCs, especially those from the core of the colonies showed a few nuclei expressing the pluripotency marker (Figure 6c). Immunoblot experiments revealed a loss in NANOG and SOX2 expression in Gal-P19SCs together with an increase in the expression of $\beta$ III-tubulin, reaching levels close to Glu-P19dCs. Although Gal-P19SCs preserved OCT4 expression, these results suggest that the stimulation of mitochondrial activity reduced stemness, triggering SC differentiation. According to this, we expected an increase in the early differentiation marker TROMA-1. However, this marker was absent in Gal-P19SCs. In addition, TROMA-1 expression, which showed high levels in Glu-P19dCs, was extremely low in Gal-P19dCs (Figure 6d).

Fluorescence images of Gal-P19SCs showing polarized mitochondria attribute a higher mitochondrial function to GalP19SCs. However, their mitochondria seem to maintain an undifferentiated morphology. Although differences regarding mtDNA copy number were not found (Supplementary Figure s7b), a higher content in NDUFB8 and MTCO1 was found in Gal-P19SCs versus Glu-P19SCs and a large increase in subunits NDUFB8, SDHB and UQCRC2 was observed in 

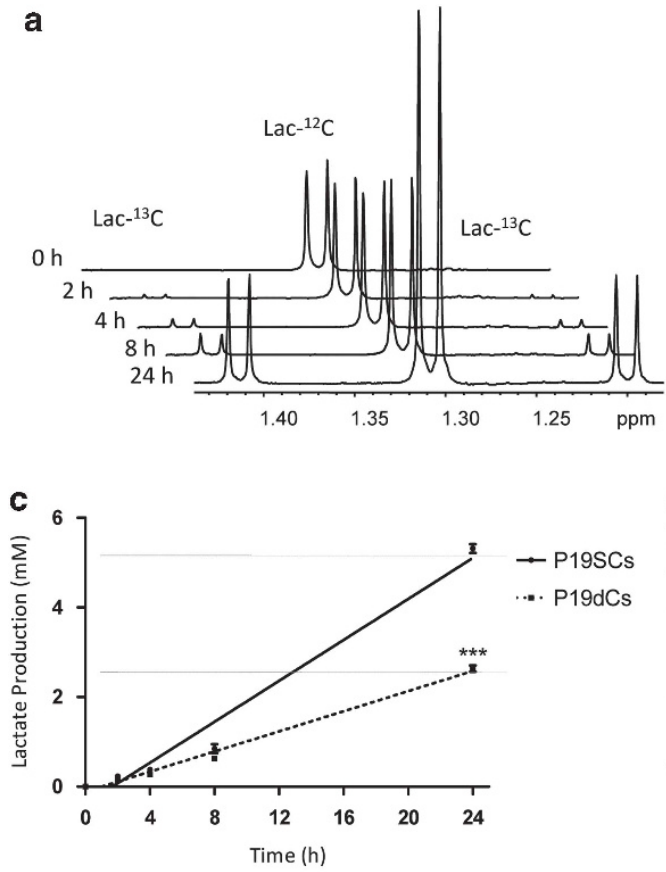

e

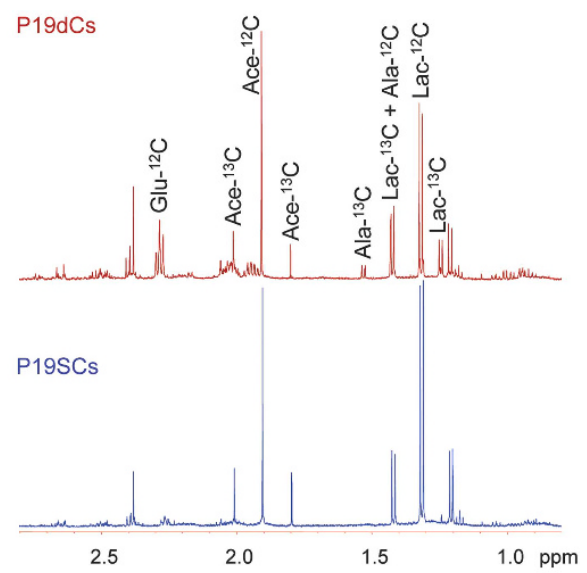

g

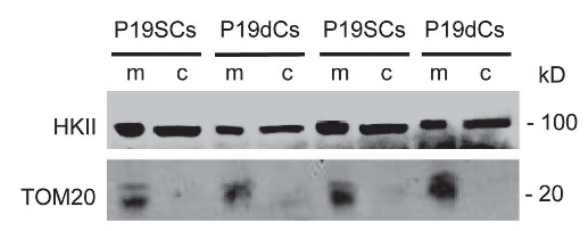

b
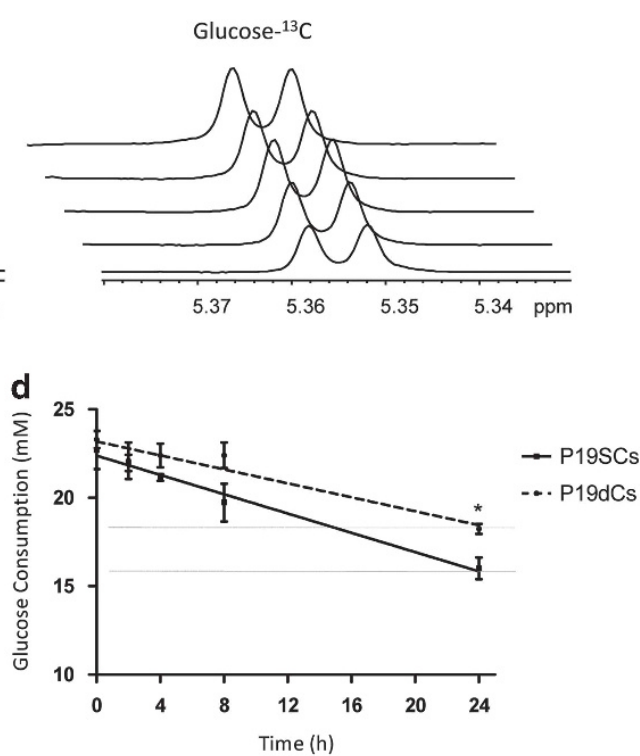

f

${ }^{13}$ C-NMR

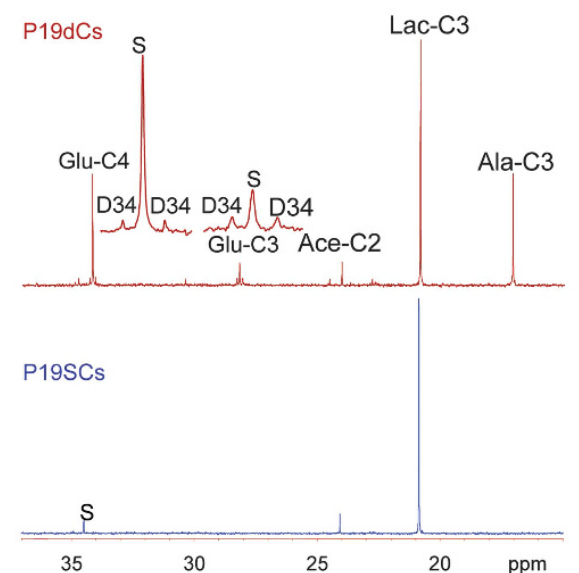

Hexokinase-II

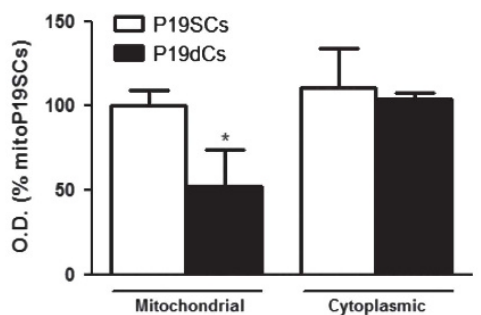

Figure 5 P19SCs display a strong glycolytic profile. (a) Appearance of $\left[3-{ }^{13} \mathrm{C}\right]-\left(\mathrm{Lac}-{ }^{13} \mathrm{C}\right)$ and unenriched $\left(\mathrm{Lac}-{ }^{12} \mathrm{C}\right)$ lactate in the culture media by ${ }^{1} \mathrm{H}-\mathrm{NMR}$. (b) Reduction in labeled glucose levels in culture media measured by ${ }^{1} \mathrm{H}-\mathrm{NMR}$ spectroscopy. (c) Comparison of lactate production over time of incubation between P19SCs and P19dCs. Values are means \pm S.E.M. from $n=6$ experiments. ${ }^{\star \star *} P<0.001$. (d) Comparison of glucose consumption between P19SCs and P19dCs. Data are means \pm S.E.M. from $n=6$ experiments. ${ }^{*} P<0.05$. (e) ${ }^{1} \mathrm{H}$-NMR metabolic profile of cell extracts for P19SCs (bottom) and P19dCs (top). (f) ${ }^{13} \mathrm{C}-\mathrm{NMR}$ spectra of cell extracts for P19SCs (bottom) and P19dCs (top). (g) Protein expression of hexokinase II (HKII) in mitochondrial (m) and cytosolic (c) extracts show a higher mitochondrial-bound hexokinase II in P19SCs. TOM20 was used as a loading control to verify mitochondrial isolation. Bar chart displays means of optical density (O.D.) \pm S.D. expressed as percentage of mitochondrial hexokinase II detected in P19SCs (mitoP19SCs), from three separate experiments. ${ }^{*} P<0.05$ 
a
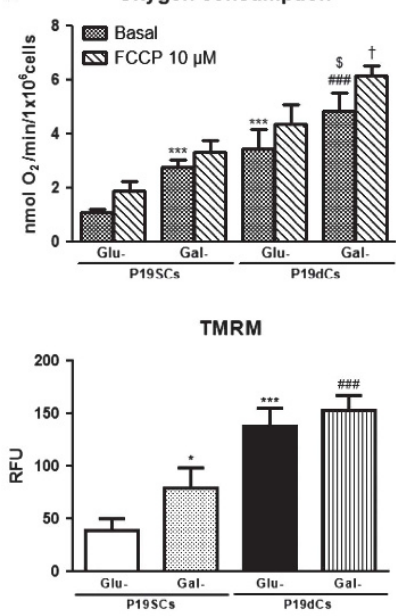

b

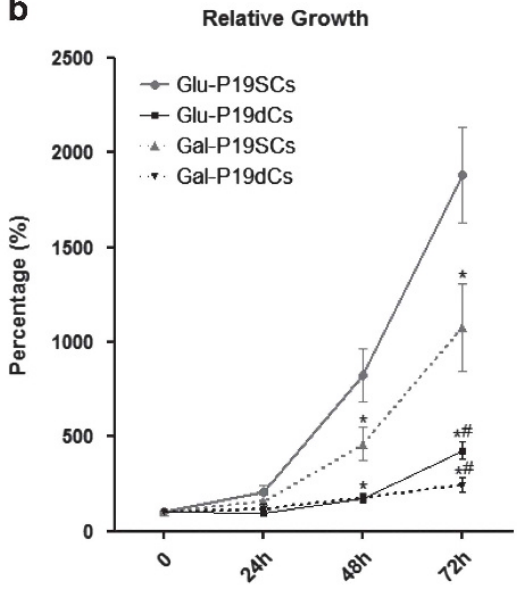

C
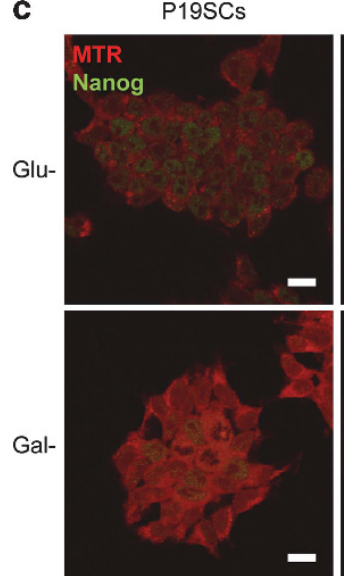

P19dCs

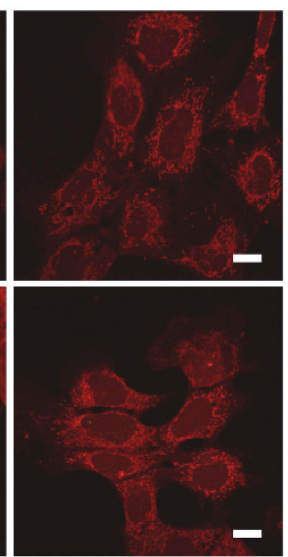

d

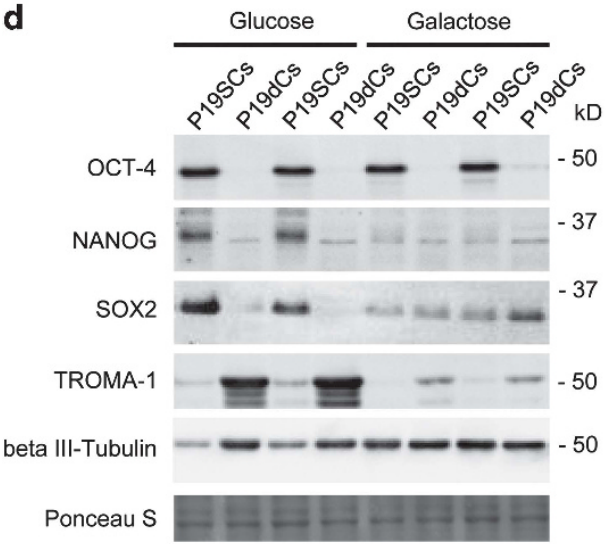

OCT4

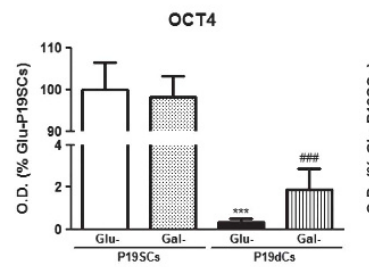

NANOG

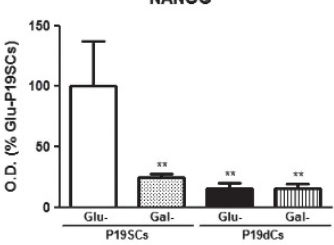

sox 2

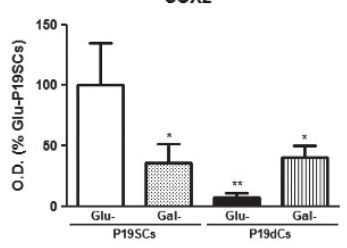

betall1-Tubulin

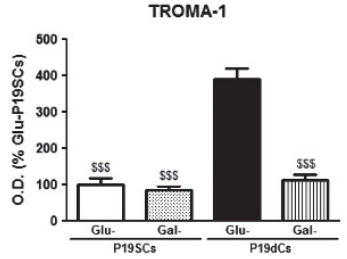

Figure 6 P19SCs grown in galactose (Gal)-containing media strengthen mitochondrial activity and differentiate. (a) Upper histogram: oxygen consumption in P19 cells: differentiated (P19dCs) and undifferentiated (P19SCs), growing in glucose (Glu)- and in Gal-containing media. FCCP was added to test maximal respiration but statistical differences were found only for Gal-P19dCs $\left({ }^{\dagger} P<0.05\right)$. Data are presented as means of nmol of $\mathrm{O}_{2}$ per minute and per $10^{6}$ cells \pm S.D. for $n=6$ experiments. Lower histogram: TMRM fluorescence measured by flow cytometry. Data are shown as relative fluorescence units (RFUs) that represent the mean average of geometric mean values \pm S.D. from at least three independent experiments. FCCP $(2 \mu \mathrm{M})$ was used as negative control and the values with FCCP were subtracted from the untreated value. Statistical comparisons: * versus Glu-P19SCs; ${ }^{*}$ versus Gal-P19SCs; ${ }^{\$}$ versus Glu-P19dCs. The number of symbols marks the level of statistical significance: one for $P<0.05$, two for $P<0.01$, and three for $P<0.001$. (b) Relative cell growth measured during $72 \mathrm{~h}$ show a decreased proliferation rate in $\mathrm{P} 19$ cells grown in galactose-containing media. Data represent the average percentage of sulforhodamine $B$ absorbance with respective time $0 \pm$ S.D. from at least three independent experiments. Statistical comparisons: ${ }^{*} P<0.05$ versus Glu-P19SCs; ${ }^{P} P<0.05$ versus Gal-P19SCs. (c) Confocal images of P19 cells stained with MitoTracker Red (MTR) and anti-NANOG antibody (FITC-green). Glu- and Gal-P19SCs express NANOG. P19dCs display a developed mitochondrial network and a loss in NANOG. Scale bar $=15 \mu \mathrm{m}$. (d) Protein levels of pluripotency (OCT4, NANOG and SOX2) and differentiation (TROMA-1 and $\beta$ Ill-tubulin) markers in all groups of P19 cells. Bar charts show means of optical density (O.D.) \pm S.D. expressed as percentage of Glu-P19SCs, from at least three separate immunoblots. Ponceau S was used for loading control. Statistical comparisons: * versus Glu-P19SCs; \# versus Gal-P19SCs; ${ }^{\$}$ versus Glu-P19dCs. The number of symbols marks the level of statistical significance: one for $P<0.05$, two for $P<0.01$ and three for $P<0.001$

Gal-P19dCs. In addition, an increase in $25 \mathrm{kDa}$ mtTFA was detected in cells grown in OXPHOS media, especially in GalP19dCs (Figure 7a). Thus, the glycolytic profile of P19 cells seems to be attenuated in Gal-P19SCs as reflected by reduction in glyceraldehyde 3-phosphate dehydrogenase (Figure 7a). As mentioned before, the measurement of mPTP opening showed a $58 \%$ fluorescence decrease in Glu-P19dCs versus Glu-P19SCs. When cells grew in OXPHOS media, a decrease of about 46\% (Gal-P19SCs versus Glu-P19SCs) was observed. Thus, changes in components controlling mPTP opening may also occur during mitochondrial differentiation induced by growing cells in OXPHOS media. On the other hand, Gal-P19dCs showed
$64 \%$ decreased fluorescence when compared with Gal-P19SCs and, again, cyclosporin A was only effective in Gal-P19SCs, increasing calcein fluorescence about $43 \%$ (Supplementary Figure s8).

These changes in mitochondrial physiology resulted in divergent effects when cells are treated with rotenone, FCCP and oligomycin. Thus, Glu-P19SCs presented higher cell viability when treated with FCCP. Meanwhile, Gal-P19SCs showed a strong susceptibility to all mitochondrial poisons, in accordance with their dependence on OXPHOS for ATP production (Figure $7 \mathrm{~b}$ ). We also analyzed the susceptibility of the four experimental groups to dichloroacetate (1, 5 and $10 \mathrm{mM})$. However, its antiproliferative effect was only 


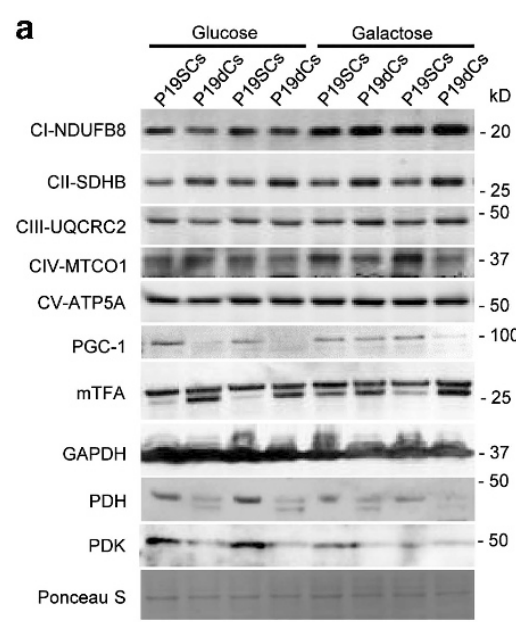

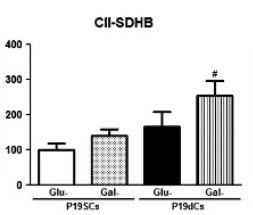
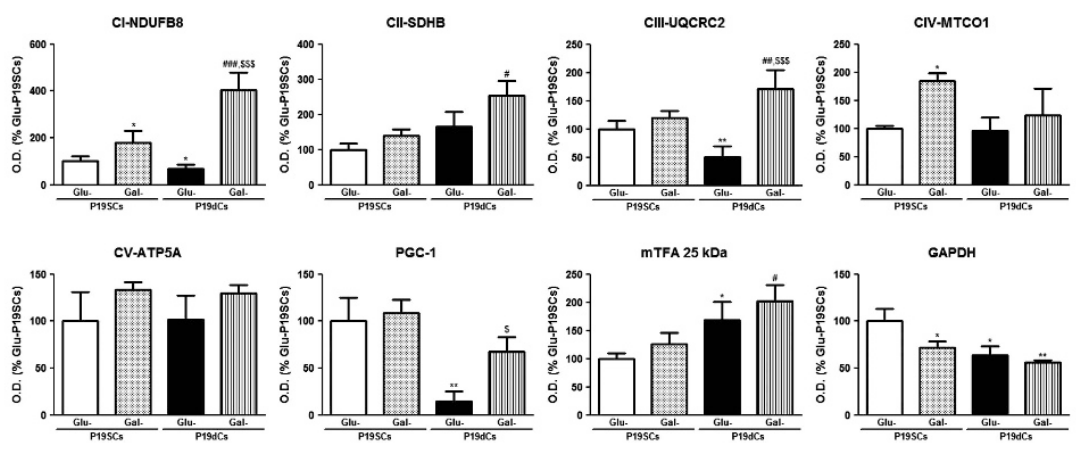

PDH
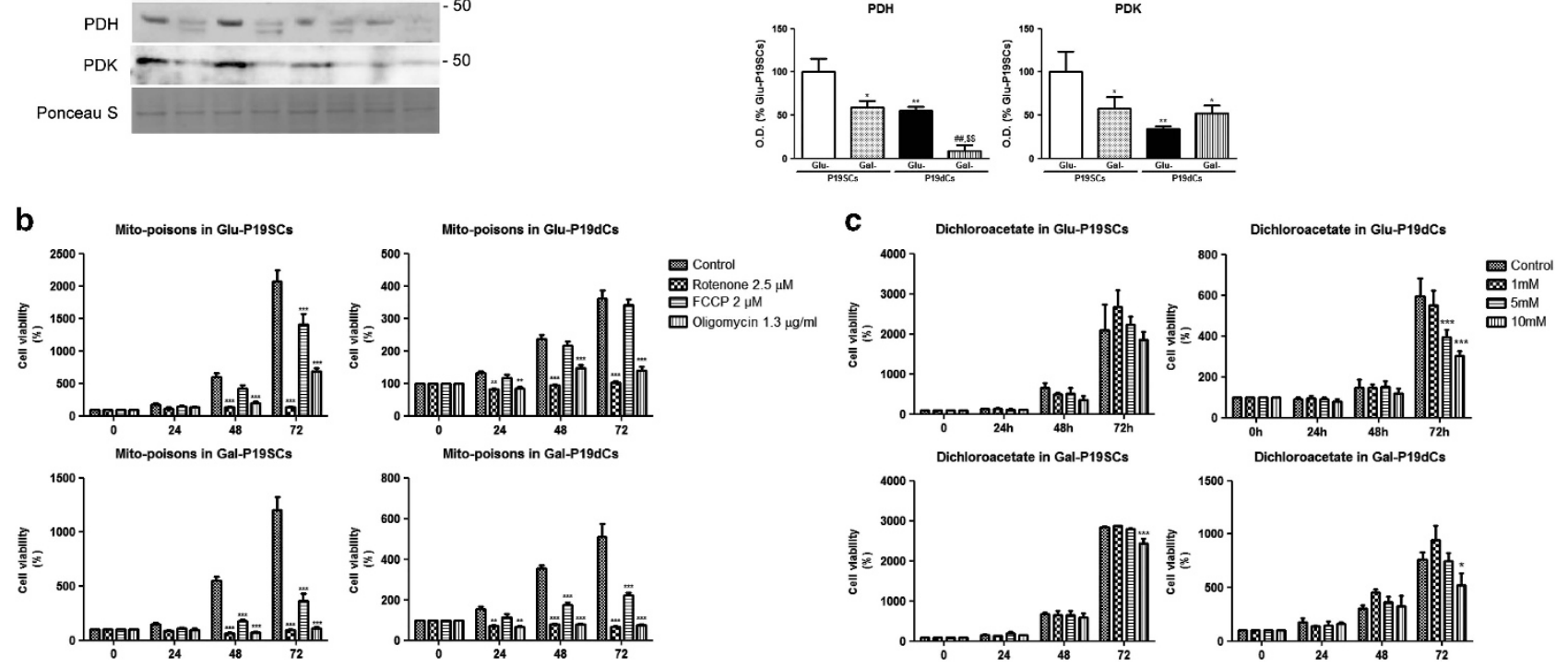

Figure 7 Mitochondrial differentiation/remodeling in P19 cells attenuates glycolytic metabolism and makes cells susceptible to mitochondrial poisons and dichloroacetate. (a) Expression of subunits of respiratory-chain complexes NDUFB8, SDHB, UQCRC2, MTC01and ATP5A; markers of mitochondrial biogenesis (PGC1 and mTFA); and markers of energetic metabolism (GAPDH, PDH and PDK) in the four types of P19 cells: stem (P19SCs) and differentiated (P19dCs) lines, growing in glucose (Glu) and in galactose (Gal)-containing media. Data are means of optical density (O.D.) \pm S.D. expressed as percentage of Glu-P19SCs, from at least three separate experiments.

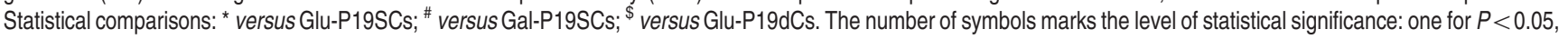
two for $P<0.01$ and three for $P<0.001$. (b) Effect of the mitochondrial poisons rotenone $(2.5 \mu \mathrm{M})$, FCCP $(2 \mu \mathrm{M})$ and oligomycin $(1.3 \mu \mathrm{g} / \mathrm{ml})$ on cell viability. Glu-P19SCs show a higher resistance against FCCP. Data are expressed as percentage of the control (vehicle only) for each time point. Data are means \pm S.E.M. from $n=5$. ${ }^{*} P<0.05$; ${ }^{* \star} P<0.01$; ${ }^{* * *} P<0.001$ versus control. (c) Viability of $\mathrm{P} 19$ cells treated with 1,5 and $10 \mathrm{mM}$ dichloroacetate. Glu-P19SCs maintain their viability. Data are expressed as percentage of the control (vehicle only) for each time point. Data are means \pm S.E.M. from $n=5$. ${ }^{\star} P<0.05 ;{ }^{* \star \star} P<0.001$ versus control

observed in cells with active mitochondria (Glu-P19dCs, Gal-P19SCs and Gal-P19dCs; Figure 7c). Curiously, resistant Glu-P19SCs showed an overexpression of the enzymes involved in dichloroacetate mechanism of action, namely pyruvate dehydrogenase kinase (PDK) and pyruvate dehydrogenase (PDH; Figure 7a).

\section{Discussion}

When P19SC cells are differentiated with RA, they lose pluripotency while retaining their immortality and some stem-like properties. This method results in endodermal cells, but may contain other early differentiated cells from neural, epithelial and fibroblast lineages. ${ }^{17}$ This mixture of differentiated cells was used as the differentiated counterpart of the P19SCs.

P19SCs and P19dCs show distinct metabolic phenotypes. While P19SCs are essentially glycolytic, allocating about $80 \%$ of consumed glucose to lactate production; P19dCs are more oxidative, reducing that percentage to about $50 \%$. This glycolytic phenotype is characteristic of cells with high proliferative rates, including many cancer and SCs. ${ }^{18}$ The much higher ${ }^{13} \mathrm{C}$ enrichment seen in glutamate, together with the presence of multiply labeled glutamate isotopomers in P19dCs, denotes a switch toward a more oxidative metabolism upon differentiation, as occurs during differentiation of human ESCs. ${ }^{19}$

According with their metabolic phenotype, mitochondria from P19SCs are structurally undeveloped, consisting of small and spherical structures predominantly located near the nucleus, which resemble mitochondria from other $\mathrm{ESCs}^{20}$ with reduced capacity to produce ATP from OXPHOS. ${ }^{10}$ Furthermore, as P19SCs differentiate, more polarized and filamentous mitochondria are formed. A higher content of PGC-1, which regulates energy homeostasis and mitochondrial activity, was observed in P19SCs. Curiously, PGC-1 was able to delay the accumulation of mis-differentiated cells and to stimulate SCs that replenish the intestinal tissue of 
Drosophila. $^{21}$ Therefore, our data support this role of PGC-1 in maintaining SC and tissue homeostasis by modulating energetic metabolism. On the other hand, our results suggest that mitochondrial biogenesis via mTFA has a causal role in inducing differentiation being activated in $\mathrm{P} 19 \mathrm{dCs}$, whereas in P19SCs, mTFA is retained in the cytoplasm in an immatureinactive form. Probably due to this, mtDNA replication is maintained at low levels in P19SCs, even during early differentiation in P19dCs. Actually, Ppargc1a was only significantly increased after a more prolonged differentiation. In fact, although it is generally accepted that mtDNA replication is enhanced during SC differentiation, a transitory decrease in mtDNA content was observed during the first days of differentiation. ${ }^{22}$ Thus, although mitochondria-related gene expression revealed dissimilar expression signatures during P19SCs differentiation, our data seem to confirm equivalent mitochondrial mass in P19SCs and P19dCs. Similarly, no significant differences in mitochondrial mass were detected between lung CSCs and non-stem cancer cells. Nevertheless, lung CSCs presented low mtDNA copy number. ${ }^{22}$ One way or the other, the number of mitochondria seems to be tightly controlled in pluripotent cells because excessive mitochondrial biogenesis can result in defective maintenance of the SC pool as described for hematopoietic $\mathrm{SCs}^{23}$

P19SCs presented low-polarized mitochondria especially in cells located at the inner core of the colonies. Curiously, only some cells from the core expressed NANOG. This phenotype may be influenced by microenvironment-specific metabolic requirements. It was described that a SC pool may require a hypoxic niche to maintain an undifferentiated status; ${ }^{24}$ even so, P19SCs grown in monolayer and under normoxia presented this phenotype. After differentiation, P19 cells lose pluripotency, do not aggregate and their mitochondria become elongated and polarized. In addition, uncoupling protein 2, which prevents mitochondrial glucose oxidation and regulates differentiation potential in pluripotent $\mathrm{SCs},{ }^{25}$ was found more present in P19SCs. This may contribute to the maintenance of a low-polarization state in mitochondria as well as to regulate metabolism in $\mathrm{P} 19 \mathrm{SCs}$.

Pluripotent cells often show more polarized mitochondria, poised to respond to an increase in energy demand during differentiation. ${ }^{26,27}$ Furthermore, a higher $\Delta \psi \mathrm{m}$ is frequently seen in cancer cells ${ }^{28}$ with this cells showing a higher propensity to form tumors. ${ }^{29}$ Nonetheless, $\Delta \psi \mathrm{m}$ is closely associated with cell differentiation and may change significantly in both directions. ${ }^{27}$ For example, increased $\Delta \psi \mathrm{m}$ was evident during differentiation of ESCs into cardiomyocytes. ${ }^{19}$ In contrast, other reports describe elevated $\Delta \psi \mathrm{m}$ in undifferentiated $\mathrm{ESCs}^{30}$ and in induced pluripotent SCs, decreasing after differentiation. ${ }^{31}$ We found that P19SCs present low $\Delta \psi \mathrm{m}$, showing small differences when treated with FCCP. Furthermore, when P19SCs were treated with FCCP, cell viability was not as heavily affected as with rotenone and oligomycin. Although the $\Delta \psi \mathrm{m}$ of differentiated cells is maintained by the ETC, that of ESCs may depend on the ATP hydrolase activity of the F1-Fo-ATPase, with glycolysis being essential for their viability promoting biosyntheticsustained growth, ${ }^{25}$ as described in rapidly proliferating cells. $^{32}$ This modulation of $\Delta \psi \mathrm{m}$ underscored its importance in SC maintenance and differentiation.

P19dCs presented higher oxygen consumption, and consequently, higher OXPHOS flux would be expected. Otherwise, when we induced the maximal respiration with FCCP, P19SCs increased oxygen consumption up to $173 \%$ of basal values, versus $126 \%$ in P19dCs. Thus, P19SCs might display a higher reserve capacity suggesting that mitochondrial respiration is not completely impaired. It was described that some pluripotent SCs possess functional OXPHOS machinery but uncouple respiration from ATP production. ${ }^{25}$ It is possible that the ETC in P19SCs operates only to recycle $\mathrm{NAD}^{+}$and keep the Krebs cycle active for the generation of biosynthetic intermediates required for high-proliferating cells. The higher resistance of P19SCs against oligomycin in terms of ATP production and their susceptibility in terms of cell growth may be ascribed to this scenario. Similar effects were observed in carbonyl cyanide m-chlorophenylhydrazonetreated ESCs, which showed an increase in pluripotency markers but slow proliferation, suggesting that these cells require some mitochondrial activity for proliferation. ${ }^{33}$ Therefore, pluripotency seems to be compromised by the activation of mitochondrial function but not by its blockage.

Our results demonstrate that mitochondria impact stemness maintenance and differentiation of P19SCs. When we forced mitochondrial metabolism, cells increased $\Delta \psi \mathrm{m}$ and respiration, reduced their proliferation and differentiated. However, the differentiation induced by forcing this metabolic switch is different from that induced by RA in cells grown in high glucose, being also different from that induced by treating Gal-P19SCs with RA, the cells with the greatest degree of mitochondrial differentiation and activity. Hence, these results demonstrate that increased mitochondrial activity per se influences the differentiation pattern, directing cells toward a neural fate, whereas inhibiting the trophectoderm pathway. This metabolic differentiation into a more efficient energetic infrastructure was also observed during early cardiomyocyte development. ${ }^{34}$ Regulators of pluripotency share points of convergence with targets associated with energy metabolism, which may impact the balance between glycolysis and oxidative metabolism. ${ }^{35}$

The activation of the mitochondrial machinery seems to be essential for SCs differentiation ${ }^{10}$ and in fact, our results revealed a remodeling in some components of the ETC after $\mathrm{RA}$-induced differentiation including a reduced expression of subunits NDUFB8 and UQCRC2. The reduction in their expression is not representative of a reduced mitochondrial activity but suggests changes in ETC dynamics, which adjusts its efficiency, producing higher amounts of ATP and superoxide anion in P19dCs. Thus, we found evident alterations on P19SC differentiation when cells were differentiated in the presence of the antioxidant $\mathrm{N}$-acetylcysteine, retaining P19 cells in a trophoectodermal stage. In fact, similar to lung CSCs that present decreased ROS and ATP in comparison with their non-stem counterpart, ${ }^{22}$ a role in stemness and differentiation was attributed to ROS. ${ }^{31}$ Likewise, it was previously showed that ROS produced by complex III stimulates differentiation of mesenchymal stromal cells, ${ }^{36}$ and that human ESCs and induced pluripotent SCs have low levels of ROS, which increase during differentiation. ${ }^{31}$ Curiously, mRNA levels of 
several mitochondrial biogenesis regulators and nuclear genes coding for the ETC decrease during in vitro differentiation of human ESCs; however, their expression increased in fully differentiated teratomas, ${ }^{31,37}$ as occurs with protein content of the analyzed ETC subunits in Gal-P19SCs and, especially, in Gal-P19dCs. These results indicate that mitochondrial biogenesis is strongly associated with differentiation. In fact, Gal-P19dCs presented the highest levels of active mTFA, increased expression of subunits from complexes I, II and III, and a higher mitochondrial activity characterized by their exclusive ability to respond to FCCP by increasing significantly oxygen consumption. We have also measured an increase in the ANT protein in P19dCs versus $\mathrm{P} 19 \mathrm{SCs}$. As the ANT is an important protein in the regulation of OXPHOS by exchanging ADP by ATP, increased ANT content can be important in the context of increased mitochondrial activity during P19 differentiation.

In addition to immature mitochondria, P19SCs showed a more closed MPTP, as well as higher CyP-D content, a regulatory component whose overexpression suppresses apoptosis. ${ }^{15}$ In fact, P19dCs presented a higher percentage of dead cells. In addition, cyclosporin A, which is thought to bind CyP-D and increase the calcium threshold for MPTP opening, closed the MPTP only in P19SCs, independently of the growth medium. Decreased mPTP open conformation state in P19SCs may explain why higher intra-mitochondrial calcium content was found, suggesting also that intrinsic defenses, such as increased CyP-D, are in place to avoid mPTP opening and mitochondrial dysfunction. Low intramitochondrial calcium found in P19dCs could contribute to stimulate mitochondrial dehydrogenases and activate OXPHOS. ${ }^{38}$ Conversely, high intra-mitochondrial calcium levels may also be considered as a possible mechanism contributing to a downregulation of OXPHOS in P19SCs. ${ }^{39}$ Furthermore, the higher calcium retention capacity of mitochondria from P19SCs could be needed to maintain low levels of cysosolic calcium, which are described to inhibit the process of cell differentiation. ${ }^{40}$

Regarding mPTP open/close differences in both cell populations there are some relevant observations. Regulation of the MPTP seems to have a physiological role during embryonic development. In fact, embryonic cardiomyocytes present immature mitochondria with a more open MPTP and during their differentiation, mPTP closure drives mitochondrial maturation. ${ }^{34}$ In our case, mitochondrial remodeling during P19 differentiation is associated with an apparent increased basal closed state of the pore. The reasons for this apparent discrepancy are not known at the moment, but it may be related with the different origins of cells, as well as with the different degree of transformation. Furthermore, a transient 'flickering' mode of mPTP opening has also been described in the literature playing a role in ROS-mediated signaling and adaptive cellular stress responses. ${ }^{41,42}$

A cyclosporin A-insensitive ionomycin-induced pore opening was also found in our cell system, similar to what was described in other types of cells, ${ }^{43}$ which could indicate alternative mitochondrial membrane permeabilization mechanisms. Ionomycin-induced MPTP opening also appeared to be dependent on differentiation state: the more undifferentiated cells (Glu-P19SCs) presented the highest resistance to pore induction. Although it is apparent that tissuespecific differences may occur, our findings suggest that mPTP regulation opening is correlated with the level of cell differentiation, which would explain the resistance to apoptosis of some pluripotent cells such as CSCs and mouse ESCs.

Hexokinase II is considered a link between mitochondrial membrane permeability and the Warburg effect. A larger amount of mitochondrial-bound hexokinase II found in P19SCs and in other types of cancer cells confers advantages for glycolytic metabolism, ${ }^{44}$ increasing also in other non-tumor pluripotent cells. ${ }^{45}$ This mitochondria-hexokinase II association seems to be determinant for mitochondrial-mediated apoptosis suppression by stabilizing a closed mPTP conformation. ${ }^{15,44}$ Indeed, increased levels of CyP-D, also observed by us in P19SCs, lead to a more extensive mitochondria-hexokinase II interaction. ${ }^{15}$

In this study, P19 cells were incubated with dichloroacetate, which reduces cell proliferation by reversing the abnormal metabolism of cancer cells from glycolysis to glucose oxidation by activating PDH through PDK inhibition. ${ }^{46} \mathrm{How}-$ ever, dichloroacetate was not effective in inhibiting proliferation of P19SCs, and interestingly, only P19 cells with active mitochondrial metabolism were susceptible to that agent. Dichloroacetate also forces rat glioma CSCs into OXPHOS but without triggering apoptosis. ${ }^{47}$ Intriguingly, the resistant and high-glycolytic P19SCs showed an overexpression of both enzymes involved in the mechanism of action of dichloroacetate (PDH and PDK), which are probably deregulated in SCs reducing substrate availability to enter the Krebs cycle.

Our findings support the relationship between metabolism and cell fate ${ }^{10}$ and confirm how metabolic signaling feeds divergent cell fates, which include mitochondrial quiescence to minimize stress, cell proliferation and self-renewal to maintain SC pool and differentiation to yield different cell types. Thus, mitochondrial metabolism seems to determine heterogeneity, self-renewal and differentiation, which are key contributing factors for the tumorigenic abilities of cancer cells. Our observations on P19SCs demonstrate that these cells rely on glycolysis for energy supply, showing immature, low-polarized and inactive mitochondria, high hexokinase II content and inactive PDH. The establishment of oxidative metabolism in P19SCs enables departure from stemness to differentiation, reduces cell proliferation and makes prone them to dichloroacetate.

\section{Materials and Methods}

Cell culture and differentiation. P19 embryonal carcinoma cells were obtained from the American Type Culture Collection (CRL-1825; Manassas, VA, USA) and cultured in glucose- or galactose (glucose-free)-containing media at $37^{\circ} \mathrm{C}$ in a $5 \% \mathrm{CO}_{2}$ atmosphere (the former denominated OXPHOS media). Highglucose Dulbecco's modified Eagle's medium (DMEM, D5648; Sigma, St. Quentin Fallavier, France) was supplemented with 10\% FBS (10270-106, Gibco, Paisley, UK), $1.8 \mathrm{~g} / \mathrm{l}$ sodium bicarbonate (S5761, Sigma), $110 \mathrm{mg} / \mathrm{l}$ sodium pyruvate (P5280, Sigma) and antibiotic/antimycotic solution (A5955, Sigma). OXPHOS medium was prepared using DMEM without glucose (D5030, Sigma) supplemented with $10 \%$ FBS, $1.8 \mathrm{~g} / \mathrm{l}$ sodium bicarbonate, $110 \mathrm{mg} / \mathrm{l}$ sodium pyruvate, $1.8 \mathrm{~g} / \mathrm{l}$ galactose (G5388, Sigma), $0.584 \mathrm{~g} / \mathrm{l} \mathrm{L-glutamine} \mathrm{(G3126,} \mathrm{Sigma)}$ and antibiotic/antimycotic solution. Undifferentiated P19 cancer cells were maintained in monolayer and passaged every $2-3$ days at a $1: 20$ to $1: 30$ dilution. To initiate differentiation, P19 cells (grown in high glucose or in OXPHOS media) were seeded at a density of $5.2 \times 10^{3} \mathrm{cells} / \mathrm{cm}^{2}$ and $1 \mu \mathrm{M}$ RA (R2625, Sigma) was added for $96 \mathrm{~h}$. 
Three-dimensional cellular spheroids were prepared during passaging using routine phosphate-buffered saline (PBS)/EDTA-trypsin protocol. Cells were seeded in a non-adhesive bacteriological-grade Petri dish at a density of about $5 \times$ $10^{4} \mathrm{cell} / \mathrm{ml}$ in fresh media with $7.5 \%$ Fetal Clone III and incubated in a regular $\mathrm{CO}_{2}$ incubator at $37^{\circ} \mathrm{C}$. During the first few days, $\mathrm{P} 19$ multicellular spheroids were small and composed of viable cells. At that moment, some of them were subjected to the differentiation protocol with $1 \mu \mathrm{M}$ RA and, after 4 days, multicellular spheroids were collected for labeling and imaging.

Cell transfection. Cells were transfected with $50 \mathrm{nM}$ of either mTFA siRNA oligonucleotide (SI02688833, Qiagen; Hilden, Germany) or with a scrambled siRNA (D-001810-03-20; Thermo Scientific, Rockford, IL, USA). To perform the assay, $24 \mathrm{~h}$ before the transfection, P19 cells were seeded at a density of $7.5 \times 10^{3} \mathrm{cell} / \mathrm{cm}^{2}$. Transient transfection was performed using Lipofectamine 2000 transfection reagent (Invitrogen, Paisley, UK) according to the manufacturer's instructions. In order to verify whether mTFA silencing influences differentiation capacity, P19 cells were subjected to the differentiation protocol $48 \mathrm{~h}$ after transfection was performed.

Cell morphology, cytochemistry and immunocytochemistry. P19 cells were seeded on glass coverslips in six-well plates for morphological studies. After completing 4 days of differentiation with RA, cell morphology was investigated by using a phase contrast light microscope (CKX 41, Olympus, Hamburg, Germany).

For immunocytochemical analysis, the incubation media were removed and cells were fixed in $4 \%$ formaldehyde in PBS during $15 \mathrm{~min}$ at $37^{\circ} \mathrm{C}$. After washing three times with PBS for $5 \mathrm{~min}$, cells were permeabilized with $0.2 \%$ Triton X-100 in PBS during 10 min. Cells were washed again three times in PBS, incubated in PBS with $1 \%$ BSA during $1 \mathrm{~h}$ at $4{ }^{\circ} \mathrm{C}$, probed with specific primary antibodies against TROMA-1 (Developmental Studies Hybridoma Bank, lowa, IA, USA), TOM20 (sc-11415; Santa Cruz Biotechnology, Santa Cruz, CA, USA) and NANOG (ab80892; Abcam, Cambridge, UK) in PBS with $1 \% \mathrm{BSA}$ for $2 \mathrm{~h}$ at $37^{\circ} \mathrm{C}$ and incubated with a dilution (1:1000 in PBS with $1 \%$ BSA) of a corresponding fluorescence-conjugated secondary antibody for $1 \mathrm{~h}$ at $37^{\circ} \mathrm{C}$. Between the labeling with primary and secondary antibodies, cells were rinsed three times with PBS for $5 \mathrm{~min}$. After labeling, coverslips were mounted on glass slides in Prolong Gold antifade medium (P36934; Invitrogen) and cells were imaged by confocal microscopy (Zeiss LSM 510Meta, Germany). Images were obtained using LSM software and were imported and incorporated into electronic figures by using Image $\mathrm{J}$ and MS PowerPoint 2010.

For mitochondrial labeling, cells were incubated with 125 nM MTR CMXRos (M7512; Invitrogen) in DMEM for 20 min at $37^{\circ} \mathrm{C}$. Staining solution was replaced with fresh prewarmed media and, when required, cells were subjected to subsequent processing steps: fixation, permeabilization and immunocytochemistry as described above.

Labeling of nuclear DNA was performed by using $1 \mu \mathrm{g} / \mathrm{ml}$ Hoechst 33342 or 300 nM DAPI (4,6-diamidino-2-phenylindole).

The fluorescent probe MitoSOX (M36008; Invitrogen) was used as mitochondrial superoxide anion indicator. P19 cells were seeded in coverslips and incubated with $5 \mu \mathrm{M}$ MitoSOX in Hank's Balanced Salt Solution (HBSS) with $\mathrm{Ca} / \mathrm{Mg}$ for $10 \mathrm{~min}$ at $37^{\circ} \mathrm{C}$. After that, cells were gently washed and mounted in warm buffer for live-cell imaging under the confocal microscope (Zeiss LSM 510Meta).

Quantification of mitochondrial morphology. To quantify mitochondrial morphology, an Image $\mathrm{J}$ macro was used. ${ }^{48}$ Pictures of P19 cells stained with MitoTracker was extracted to grayscale, inverted to show mitochondria-specific fluorescence as black pixels, and thresholded to optimally resolve individual mitochondria. The mean area/perimeter ratio was employed as an index of mitochondrial interconnectivity and inverse circularity used as a measure of mitochondrial elongation.

Electron microscopy. Electron microscopy was performed to examine organelle structural characteristics in both P19SCs and P19dCs. Cells were trypsinized and fixed for electron microscopy in $3 \%$ glutaraldehyde in cacodylate buffer ( $0.1 \mathrm{M}$ sodium cacodylate buffer), $\mathrm{pH} 7.3$ for $2 \mathrm{~h}$ at $4{ }^{\circ} \mathrm{C}$. Cells were then centrifuged for $3 \mathrm{~min}$ at $2500 \times \mathrm{g}$, washed with cacodylate buffer and incubated in $1 \% \mathrm{OsO}_{4}$ in cacodylate buffer for $2 \mathrm{~h}$. Pellets were again washed in cacodylate buffer and embedded in $1 \%$ agar. Samples were then dehydrated in ethanol and embedded in Spurr's resin. An LKB ultra-microtome Ultrotome III (GE Healthcare, Buckinhamshire, UK) was used to obtain thin sections that were subsequently stained with methanolic uranyl acetate followed by lead citrate. Sections were examined with a JEOL Jem-100SX electron microscope (JEOL, Tokyo, Japan) operated at $80 \mathrm{kV}$. Forty micrographs of each sample were taken to examine mitochondrial morphology in both groups of cells.

Mitochondrial transmembrane electric potential $(\Delta \psi \mathrm{m})$. Mitochondria were also labeled using the potentiometric dye TMRM (tetramethylrhodamine methyl ester). Cells were seeded as described above in an open $\mu$-Slide (chambered coverslip) with eight wells (80826; Ibidi, Martinsried, Germany) and incubated with $100 \mathrm{nM}$ TMRM (T668; Invitrogen) and $1 \mu \mathrm{g} / \mathrm{ml}$ Hoechst 33342 (Invitrogen) for $30 \mathrm{~min}$ at $37^{\circ} \mathrm{C}$. Because of the low fluorescence of the probes in the extracellular media, the images were collected without replacing the cell culture media using confocal microscopy (Zeiss LSM 510Meta). For vital labeling of P19 multicellular spheroids, spheroids were removed from the non-adhesive bacteriological-grade dishes and transferred to glass-bottom 30-mm diameter culture dishes from Mat-Tek (Ashland, MA, USA). Under stirring, the medium in the glass-bottom dish multicellular spheres was incubated with $1 \mu \mathrm{g} / \mathrm{ml}$ Hoechst, $100 \mathrm{nM}$ TMRM and, if needed, with $2.5 \mu \mathrm{M}$ calcein-aceto-methyl ester (calcein-AM; C3100MP, Invitrogen). Finally, the dish was placed in a $\mathrm{CO}_{2}$ incubator for about $1 \mathrm{~h}$ before imaging with the confocal microscope (Zeiss LSM 510Meta).

The $\Delta \psi \mathrm{m}$ in $\mathrm{P} 19$ cells was also investigated by measuring TMRM fluorescence by flow cytometry (Becton Dickinson FACScalibur, Becton Dickinson, San Jose, CA, USA). Cells were seeded at concentrations described above and twenty-four hours after seeding, cells were subjected to the differentiation protocol with RA. After differentiation, cells were trypsinized and treated with $150 \mathrm{nM}$ TMRM for $30 \mathrm{~min}$ and then evaluated for mean cell fluorescence by flow cytometry. The uncoupler carbonyl cyanide 4-(trifluoromethoxy)phenylhydrazone (FCCP; $2 \mu \mathrm{M}$ ) was used as a control and was added $15 \mathrm{~min}$ after TMRM treatment to promote mitochondrial depolarization.

P19 cells were also loaded with green-fluorescing MitoTracker Green FM (M7514, Invitrogen) at $0.5 \mu \mathrm{M}$ for $30 \mathrm{~min}$ at $37^{\circ} \mathrm{C}$ to label mitochondria regardless of mitochondrial membrane potential. ${ }^{49}$ Loading of MitoTracker Green was performed before co-loading with red-fluorescing TMRM $(1 \mu \mathrm{M})$ for $30 \mathrm{~min}$ in identical conditions to monitor $\Delta \psi \mathrm{m}$ by serial imaging after depolarization with $2 \mu \mathrm{M} \mathrm{FCCP}$. As TMRM quenches MitoTracker Green fluorescence by fluorescence resonance energy transfer, release of TMRM from mitochondria after depolarization leads to unquenching of MitoTracker Green fluorescence. ${ }^{50}$ To confirm and quantify the results, the experiment was repeated using simultaneous incubation of MitoTracker Green and TMRM and measurement by flow cytometry (Becton Dickinson FACScalibur). MTG was also loaded alone to roughly compare the amount of mitochondria between both types of P19 cells.

Mitochondrial DNA copy number. Genomic and mitochondrial DNA were isolated from P19SCs and P19dCs using the GenElute Mammalian Genomic DNA Miniprep Kit (G1N70; Sigma). Quantitative real-time PCR was performed using the LightCycler System (Roche Diagnostics, Indianapolis, IN, USA) with the following reaction components: $3.6 \mu \mathrm{l}$ water, $0.2 \mu \mathrm{l}(0.2 \mu \mathrm{M})$ forward primer, $0.2 \mu \mathrm{l}$ $(0.2 \mu \mathrm{M})$ reverse primer, $5 \mu \mathrm{l}(1 \times)$ SYBR Premix Ex TaqTM and $1 \mu \mathrm{l}$ DNA sample $(2 \mathrm{ng})$ as PCR template. Primers used were $5 \mathrm{COI}$ and $3 \mathrm{COI}$ for $\mathrm{mtDNA}^{51,52}$ and MuRTGADD45a (5'-ACCCCGATAACGTGGTACTG-3') and MuGADD45R (5;- TGACCCGCAGGATGTTGATG-3') mouse GADD45 genomic DNA primers for genomic DNA determination. LightCycler glass capillaries were filled with the $10 \mu \mathrm{l}$ mixture, capped, centrifuged and placed onto the LightCycler rotor. The experimental LightCycler run protocol used the following steps: denaturation program $\left(95^{\circ} \mathrm{C}\right.$ for $\left.30 \mathrm{~s}\right)$, amplification and quantification program repeated 50 times $\left(95^{\circ} \mathrm{C}\right.$ for $5 \mathrm{~s}, 60^{\circ} \mathrm{C}$ for $20 \mathrm{~s}, 72^{\circ} \mathrm{C}$ for $\left.20 \mathrm{~s}\right)$, melting curve program $\left(95-45-95^{\circ} \mathrm{C}\right.$ with a final heating rate of $0.1^{\circ} \mathrm{C} / \mathrm{s}$ and continuous fluorescent measurement), and finally a cooling step to $40^{\circ} \mathrm{C}$. Crossing points for mtDNA were compared against genomic DNA for data analysis.

Cellular oxygen consumption. Oxygen consumption was measured polarographically with a Clark-type Oxygen electrode (Yellow Springs Instruments, Model YSI 5331, Yellow Springs, OH, USA) connected to a recorder (Kipp\&Zonen, model BD 121, Delft, The Netherlands) in a thermostated water-jacketed closed chamber with magnetic stirring. The reactions were performed at $37^{\circ} \mathrm{C}$ in $1 \mathrm{ml}$ of the corresponding growth medium (glucose- or OXPHOS medium) with $5 \times$ $10^{6}$ cells. Respiration was sustained with endogenous substrates followed by uncoupling by FCCP $(2-10 \mu \mathrm{M})$. Respiration rates were obtained assuming an oxygen concentration of $237 \mathrm{nmol} \mathrm{O} / \mathrm{ml}$ in the experimental medium at $37^{\circ} \mathrm{C}^{53}$ 
In order to confirm the measurement of mitochondrial basal respiration, $1.5 \mu \mathrm{M}$ rotenone was added to completely stop oxygen consumption by inhibition of mitochondrial complex I (NADH ubiquinone oxidoreductase).

Adenine nucleotide measurement (ATP/ADP/AMP). ATP, ADP and AMP levels were measured in P19SCs and P19dCs by HPLC. For adenine nucleotide extraction, after one rinse in cold PBS, $0.5 \mathrm{ml}$ PBS and $0.5 \mathrm{ml}$ perchloric acid/EDTA were added to each dish. Cells were scraped from the dishes, placed in $1 \mathrm{ml}$ micro-centrifuge tubes and centrifuged for $2 \mathrm{~min}$ at $14000 \times \mathrm{g}$. Pellets were re-suspended in $50 \mu \mathrm{l}$ of $1 \mathrm{M} \mathrm{NaOH}$ and later used for protein quantification by the BCA protein assay (23227, Thermo Scientific). Supernatant was neutralized with $3 \mathrm{M} \mathrm{KOH}$ in $1.5 \mathrm{M}$ Tris and centrifuged again. The supernatant was again collected and stored at $-80^{\circ} \mathrm{C}$ until analyzed by reverse-phase high-performance liquid chromatography. The chromatographic apparatus was a Beckman-System Gold, consisting of a 126 Binary Pump Model and a 166 Variable UV detector, controlled by computer (Beckman Coulter, Brea, CA, USA). The detection wavelength was $254 \mathrm{~nm}$, and the column was a Lichrospher 100RP-18 from Merck (Darmstadt, Germany). An isocratic elution with $100 \mathrm{mM}$ phosphate buffer $\left(\mathrm{KH}_{2} \mathrm{PO}_{4}\right), \mathrm{pH} 6.5$ and $1 \%$ methanol was performed with a flow rate of $1 \mathrm{ml} / \mathrm{min}$. The time required for each analysis was $5 \mathrm{~min}$.

mPTP opening. Determination of mPTP opening was performed using the MitoProbe Transition Pore Assay (M34153; Invitrogen) by co-loading with calcein$\mathrm{AM}$ and $\mathrm{CoCl}_{2}$ as previously described. ${ }^{54}$ Calcein-AM passively diffuses into the cells and accumulates in cytosolic compartments, including mitochondria. Once inside cells, intracellular esterases cleave the acetoxymethyl esters to release the polar fluorescent dye calcein, which does not cross mitochondrial or plasma membranes. The fluorescence from cytosolic calcein is quenched by the addition of $\mathrm{CoCl}_{2}$, whereas the fluorescence from mitochondrial calcein is maintained as $\mathrm{CoCl}_{2}$ is not permeable to intact mitochondrial membranes. Inner mitochondrial membrane permeability to $\mathrm{CoCl}_{2}$ indicates opening of the mPTP. Thus, mitochondrial calcein fluorescence intensity is weaker when mPTP is open than when closed.

In brief, $10^{6} \mathrm{P} 19$ cells in HBSS/Ca was loaded with $0.01 \mu \mathrm{M}$ calcein-AM and $0.4 \mathrm{mM}$ $\mathrm{CoCl}_{2}$ for $15 \mathrm{~min}$ at $37^{\circ} \mathrm{C}$, washed to remove the excess of staining and analyzed using a flow cytometer (Becton Dickinson FACScalibur) with $488 \mathrm{~nm}$ excitation and emission filters appropriate for fluorescein. As a control, cells loaded with calcein $\mathrm{AM}$ and $\mathrm{CoCl}_{2}$ were also treated with ionomycin $(0.5 \mu \mathrm{M})$ to allow entry of excess $\mathrm{Ca}^{2+}$ into the cells to trigger mPTP activation and subsequent loss of mitochondrial calcein fluorescence. The ionomycin response was blocked by pre-treating cells with cyclosporine $\mathrm{A}(2 \mu \mathrm{M})$, a compound reported to be a mPTP de-sensitizing agent. ${ }^{55}$

Data were displayed in relative fluorescence units and represent the mean average of geometric mean values normalized to calcein fluorescence of cells incubated only with calcein-AM from three different experiments.

Calcium measurements. Intracellular calcium levels were measured as described in the Fluo-4 Direct Calcium Assay kit (F10472, Invitrogen). ${ }^{56}$ After seeding $5 \times 10^{5}$ cells in 96-well plates, the medium was removed and $50 \mu$ l of prewarmed HBSS were added. The Fluo-4 Direct calcium reagent was prepared as described and added in a final concentration of $2.5 \mathrm{mM}$ to the plate wells containing HBSS. The plates incubated for $30 \mathrm{~min}$ at $37^{\circ} \mathrm{C}$ and the fluorescence (excitation at $494 \mathrm{~nm}$ and emission at $516 \mathrm{~nm}$ ) was measured in a fluorescence multi-plate reader (Gemini EM; Molecular Devices, Sunnyvale, CA, USA).

Mitochondrial calcium content was measured using the fluorescent indicator Rhod-2 (R-1245MP, Invitrogen) and following the manufacturer's instructions. ${ }^{57}$ Briefly, $7.5 \times 10^{4}$ cells in 24-well plates were loaded with $5 \mu \mathrm{M}$ Rhod-2 by incubation in low-calcium Krebs solution during $40 \mathrm{~min}$ at $37^{\circ} \mathrm{C}$. Cells were then washed with Krebs solution (without calcium) for $30 \mathrm{~min}$. Cell fluorescence was measured (excitation at $552 \mathrm{~nm}$, emission at 581) in a fluorescence plate reader (Gemini EM). Calcium storage capacity of mitochondria was measured by monitoring Rhod-2 fluorescence during $10 \mathrm{~min}$ under $10 \mu \mathrm{M}$ ionomycin-mediated cell calcium overload.

Western blot analysis. In order to obtain total cellular extracts, P19 cells were harvested by trypsinization, washed with PBS and centrifuged for 5 min at $1000 \times g$. The cellular pellet was resuspended in RIPA buffer (R0278; Sigma) supplemented with $2 \mathrm{mM}$ dithiothreitol, $100 \mu \mathrm{M}$ phenylmethylsulfonyl fluoride) and a protease inhibitor cocktail (containing $1 \mu \mathrm{g} / \mathrm{ml}$ of leupeptin, antipain, chymostatin and pepstatin $\mathrm{A}$ ), physically ruptured by sonication and kept at $-80^{\circ} \mathrm{C}$ until used.
Protein contents were determined by using the BCA protein assay (23227; Thermo Scientific). After denaturation at $95^{\circ} \mathrm{C}$ for $5 \mathrm{~min}$ in a Laemmli buffer (161-0737; Bio-Rad, Hercules, CA, USA), equivalent amounts of protein $(50 \mu \mathrm{g})$ were separated by electrophoresis in 8 or $12 \%$ SDS-polyacrylamide gel and electrophoretically transferred to a polyvinylidene difluoride membrane. Ponceau S staining was used to ensure equal loading. After blocking membranes with $5 \%$ skim milk in TBS-T (50 mM Tris- $\mathrm{HCl}$, pH 8; $154 \mathrm{mM} \mathrm{NaCl}$ and 0.1\% Tween-20) for $1 \mathrm{~h}$ at room temperature, membranes were incubated overnight at $4{ }^{\circ} \mathrm{C}$ with the antibodies directed against $\beta$ III-Tubulin (sc80005), PGC-1 (sc13067), mTFA (sc23588), TOM20 (sc11415), PDK (sc28783), ANT (sc9299) from Santa Cruz Biotechnology; OCT4 (2840), SOX2 (2748), Musashi (2154), COX IV (4844), GAPDH (5174), PDH (3205) from Cell Signaling (Danvers, MA, USA); Nanog (ab80892), NDUFB8 (ab110242), SDHB (ab14714), UQCRC2 (ab14745), MTCO1 (ab14705), ATP5A (ab14748), VDAC (ab34726), CyP-D (ab110324) from Abcam; Troma-1 (Developmental Studies Hybridoma Bank), $\alpha$-Tubulin (T5168, Sigma) and actin (MAB1501; Millipore, Billerica, MA, USA), each previously diluted 1:1000 in blocking buffer ( $1 \%$ skim milk in TBS-T). After three 5-min washes in PBS-T, the membranes were incubated with a dilution (1:10000 in blocking buffer) of a corresponding alkaline phosphatase-conjugated secondary antibody (Santa Cruz Biotechnology) for $2 \mathrm{~h}$ at room temperature. After three 15-min washes in PBS-T, membranes were developed with the ECF detection system (RPN5785; GE Healthcare, Piscataway, NJ, USA) and imaged with Versa Doc imaging system (Bio-Rad) according to the manufacturers' protocols. Densities of each band were calculated with Quantity One Software (Bio-Rad). All data presented are representative from at least three separate experiments.

Isolation of mitochondrial extracts. Mitochondrial extracts were isolated harvesting P19 cells by trypsinization and spinning them down at $1000 \times$ g. Pellets were washed once in cold PBS and centrifuged again $(1000 \times g)$ at $4{ }^{\circ} \mathrm{C}$. The cell suspension was then resuspended in $0.5 \mathrm{ml}$ of ice-cold sucrose buffer $(250 \mathrm{mM}$ sucrose, $20 \mathrm{mM} \mathrm{K}^{+}$HEPES pH7.5, $10 \mathrm{mM} \mathrm{KCl}, 1.5 \mathrm{mM} \mathrm{MgCl}_{2}, 0.1 \mathrm{mM}$ EDTA, $1 \mathrm{mM}$ EGTA) supplemented right before use with $1 \mathrm{mM}$ dithiothreitol, $0.1 \mathrm{mM}$ phenylmethylsulfonyl fluoride and protease inhibitor cocktail containing $1 \mu \mathrm{g} / \mathrm{ml}$ of leupeptin, antipain, chymostatin and pepstatin. Then, it was incubated on ice for 20-30 min. After incubation, cells were transferred to a pre-cooled tissue homogenizer and homogenized 30 times using a tight pestle, while keeping the homogenizer on ice. The progress was monitored every 20-30 strokes under a phase contrast microscope and was stopped when more than $90 \%$ of cells were burst.

Homogenized cells were centrifuge at $3500 \times \mathrm{g}$ for $5 \mathrm{~min}$ at $4^{\circ} \mathrm{C}$. The supernatant was collected containing mitochondrial and cytosolic fraction. Then, the collected supernatant was centrifuged again at $10000 \times g$ during $15 \mathrm{~min}$ at $4{ }^{\circ} \mathrm{C}$. The pellet, corresponding to the mitochondrial fraction was resuspended in $50 \mu \mathrm{l}$ of sucrose buffer cited above. The supernatant was again centrifuged at $100000 \times g$ during $30 \mathrm{~min}$ at $4{ }^{\circ} \mathrm{C}$. The resulting supernatant contains the cytosolic fraction and in order to concentrate the protein was lyophilized and resuspended in $50 \mu \mathrm{l}$ of the same sucrose buffer.

Specific proteins in both fractions were semi-quantified by western blotting as described above using antibodies against hexokinase II (2867; Cell Signaling), mTFA (sc23588; Santa Cruz Biotechnology) and TOM20 (sc-11415; Santa Cruz Biotechnology).

NMR. Metabolic analysis was performed by NMR analysis of culture medium and cell extracts. The culture media were supplemented with $\left[1-{ }^{13} \mathrm{C}\right]$ glucose to monitor rates of lactate production by the appearance of $\left[3^{13} \mathrm{C}\right]$ lactate in the culture medium, and of Krebs cycle flux by analysis of ${ }^{13} \mathrm{C}$ labeling patterns of glutamate from the cell extract.

${ }^{1} \mathrm{H}$-NMR spectra of cell culture media and cell methanol/water $(80 \% / 20 \%$; v/v) extracts were acquired on a 600-MHz NMR Spectrometer (Varian-Agilent Technologies, Santa Clara, CA, USA), using a 3-mm indirect detection probe. Each spectrum consisted of either 32 (culture media) or 128 (cell extracts) averaged scans to ensure adequate signal-to-noise ratios for metabolite quantification. Acquisition parameters included a $45^{\circ}$ radiofrequency excitation pulse, a 3-s acquisition time, providing a total of $21.6 \mathrm{k}$ points covering a sweep width of $7.2 \mathrm{k} \mathrm{Hz}$, an interpulse delay of $10 \mathrm{~s}$ to ensure complete relaxation of all nuclei in the sample, and a 3-s solvent pre-saturation to avoid excessive signal due to the solvent $\left(\mathrm{H}_{2} \mathrm{O}\right)$, especially in the cell culture media samples. Each of these samples consisted of $160 \mu \mathrm{l}$ of culture media supplemented with $40 \mu \mathrm{l}$ of a solution of sodium fumarate $(10 \mathrm{mM})$ dissolved in phosphate $(100 \mathrm{mM})$ buffered $\mathrm{D}_{2} \mathrm{O}(99.9 \%)$, used as internal standard. For cell extracts, the lyophilized powder was dissolved in $160 \mu \mathrm{L}_{2} \mathrm{O}$ 
(99.9\%) and the same $40 \mu \mathrm{l}$ of internal standard were added. Cell extracts were also used for ${ }^{13} \mathrm{C}$-NMR spectra acquisition toward performing ${ }^{13} \mathrm{C}$ isotopomer analysis. ${ }^{13} \mathrm{C}$-NMR spectra were acquired in the same spectrometer using a 3-mm dual band (broadband) probe. Typical acquisition parameters included a $45^{\circ}$ radiofrequency excitation pulse, a 2.5-s acquisition time, providing $125 \mathrm{k}$ points for definition of a $50-\mathrm{kHz}$ sweep width and a pre-delay of $0.5 \mathrm{~s}$, allowing an interpulse delay of $3 \mathrm{~s}$ which ensures full relaxation of aliphatic carbons from most metabolites, namely glutamate, lactate and alanine.

Cell viability/proliferation. Cell proliferation was measured by the SRB assay as described previously. ${ }^{58} \mathrm{P} 19$ cells were seeded in 48-well plates at a concentration of $0.5 \times 10^{4} \mathrm{cells} / \mathrm{ml}$ for P19SCs and $2 \times 10^{4} \mathrm{cells} / \mathrm{ml}$ for P19dCs. Twenty-four hours after seeding, specific wells were treated with mitochondrial poisons rotenone $(2.5 \mu \mathrm{M})$, FCCP $(2 \mu \mathrm{M})$ and oligomycin $(1.3 \mu \mathrm{g} / \mathrm{ml})$, as well as with dichloroacetate $(1,5$ and $10 \mathrm{mM})$ to evaluate their cytotoxic effect in P19 cells.

After 24, 48 and $72 \mathrm{~h}$, the medium was removed and wells rinsed with $1 \%$ PBS. Cells were then fixed by adding $1 \%$ acetic acid in $100 \%$ methanol for at least $2 \mathrm{~h}$ at $-20^{\circ} \mathrm{C}$. Later, the fixation solution was discarded and the plates dried in an oven at $37^{\circ} \mathrm{C}$. Two hundred and fifty microliters of $0.5 \%$ SRB in $1 \%$ acetic acid solution were added and incubated at $37^{\circ} \mathrm{C}$ for $1 \mathrm{~h}$. The wells were then washed with $1 \%$ acetic acid in water and dried. Then, $500 \mu \mathrm{l}$ of Tris, $\mathrm{pH} 10$ was added and the plates were shaken for $30 \mathrm{~min}$. Finally, $200 \mu \mathrm{l}$ of each supernatant was transferred in 96-well plates and optical density was measured at $540 \mathrm{~nm}$.

Live/dead assay. Calcein-AM (C1430; Invitrogen) and PI; (P4864; Sigma Aldrich) were used to determine the percentages of viable and dead cells. Briefly, light-protected $10^{6} \mathrm{P} 19$ cells in HBSS/Ca were loaded with $0.1 \mu \mathrm{M}$ calcein and $80 \mu \mathrm{M} \mathrm{PI}$ for $20 \mathrm{~min}$ at room temperature. The fluorescence was measured by FACS (Becton Dickinson FACScalibur) with $488 \mathrm{~nm}$ excitation wavelength. The simultaneous measurement of Calcein/PI fluorescence was performed using 530/ $30 \mathrm{~nm}$ bandpass filter for Calcein and a 610/20 nm bandpass filter for PI red fluorescence.

Quantitative gene expression analysis. RNA was isolated from P19 cells using RNeasy kit (74104; Qiagen). Expression levels of Ppargc1a, MtfA, Ant-1, Ant-2, Vdac-1, Vdac-2, Vdac-3, Gapdh, 3-phosphoglycerate dehydrogenase and the housekeeping gene $18 \mathrm{~S}$ were determined using RT-qPCR. Primer pairs used for RT-PCR were for Ppargc1a: 5'-CAAATGACCCCAAGGGTTCCCC-3', 5'-GGTGGCACCACGGTCTTGCAA-3'; MttA: 5'-GCAGCCCTGTGGAGGGAG CT-3', 5'-TCTGCCGGGCCTCCTTCTCC-3'; Ant-1: 5'-CGCCCCGATCGA GAGGGTCA-3' 5' $^{\prime}$-TATGGCGATCCACGCCTCCCA-3'; Ant-2: 5'-AGCTGATGT GGGCAAAGCTGGAG-3', 5'-CAGCGACAGCAGTGACAGACTGTG-3'; Vdac-1: 5'-CGCCTCCGAGAACATGGCCGT-3', $5^{\prime}$-TGGTTTCCGTGTTGGCAGAGCC-3'; Vdac-2: 5'-ATGCCCACGGCCGATGTGTA-3'， 5'-ACTTGGTCTCCAAGGTCC CGCT-3'; Vdac-3: 5'-GGGCCCACCCTCGGGTTGTA-3', 5'-TGACCATGCCA AACCCATACCCT-3'.

Total RNA was isolated from P19 cells and $0.5-1.0 \mathrm{mg}$ of RNA were reverse transcribed to DNA in $20 \mathrm{ml}$ reaction volume using oligo(dTs) with the AffinityScript QPCR cDNA Synthesis kit (600559; Stratagene, Santa Clara, CA, USA). Two control reactions were included; one was without Reverse Transcriptase and the other without RNA. PCR was performed using $2 \times$ Brilliant SYBR Green QPCR Master Mix (600828; Stratagene). Triplicate cDNA samples were run and average crossing threshold $(\mathrm{Ct})$ values calculated. Relative gene expressions were calculated as $2 \mathrm{Ct}(18 \mathrm{~S})$ - Ct(gene). $18 \mathrm{~S}$ was used as a normalizing gene.

Statistical analyses. Data are mean values \pm S.D. calculated from at least three separate experiments. Statistical comparisons between P19SCs and $\mathrm{P} 19 \mathrm{dCs}$ were carried out using the Student's $t$-test. The non-parametric test Mann-Whitney was applied in non-normal data. Multiple comparisons were performed using ANOVA followed by the Bonferroni post-hoc test. Significance was accepted with $P<0.05$.

\section{Conflict of Interest}

The authors declare no conflict of interest.

Acknowledgements. We thank Isabel Nunes Correia and Luisa Cortes for technical assistance. This work was performed with funding from the Portuguese
Foundation for Science and Technology (FCT) co-funded by COMPETE/FEDER/ National Budget (PTDC/QUI-BIQ/101052/2008 and PEst-C/SAU/LA0001/20132014). Vega-Naredo I acknowledges a Marie Curie Intra-European Fellowship from the EU Seventh Framework Programme (PIEF-GA-2009-251850) and the FCT (SFRH/BPD/86534/2012). The FCT also supported Mesquita KA (SFRH/BD/66138/2009). The present work was also supported by QREN project \# 4832, reference 'CENTRO-07-ST24-FEDER-002008'.

1. McBurney MW, Jones-Villeneuve EM, Edwards MK, Anderson PJ. Control of muscle and neuronal differentiation in a cultured embryonal carcinoma cell line. Nature 1982; 299: 165-167.

2. McBurney MW. P19 embryonal carcinoma cells. Int J Dev Biol 1993; 37: 135-140.

3. Mummery CL, Feijen A, Moolenaar WH, van den Brink CE, de Laat SW. Establishment of a differentiated mesodermal line from P19 EC cells expressing functional PDGF and EGF receptors. Exp Cell Res 1986; 165: 229-242.

4. Tang C, Ang BT, Pervaiz S. Cancer stem cell: target for anti-cancer therapy. FASEB J 2007; 21: 3777-3785.

5. Doss CG, Debajyoti C, Debottam S. Disruption of mitochondrial complexes in cancer stem cells through nano-based drug delivery: a promising mitochondrial medicine. Cell Biochem Biophys 2013; 67: 1075-1079.

6. Loureiro R, Mesquita KA, Oliveira PJ, Vega-Naredo I. Mitochondria in cancer stem cells: a target for therapy. Recent Pat Endocr Metab Immune Drug Discov 2013; 7: 102-114.

7. Watkins J, Basu S, Bogenhagen DF. A quantitative proteomic analysis of mitochondrial participation in p19 cell neuronal differentiation. J Proteome Res 2008; 7: 328-338.

8. Barbosa IA, Machado NG, Skildum AJ, Scott PM, Oliveira PJ. Mitochondrial remodeling in cancer metabolism and survival: potential for new therapies. Biochim Biophys Acta 2012; 1826: 238-254.

9. Poteet E, Choudhury GR, Winters A, Li W, Ryou MG, Liu R et al. Reversing the Warburg effect as a treatment for glioblastoma. J Biol Chem 2013; 288: 9153-9164.

10. Folmes CD, Dzeja PP, Nelson TJ, Terzic A. Metabolic plasticity in stem cell homeostasis and differentiation. Cell Stem Cell 2012; 11: 596-606.

11. Lonergan T, Bavister B, Brenner C. Mitochondria in stem cells. Mitochondrion 2007; 7: 289-296.

12. Gordon JW, Rungi AA, Inagaki H, Hood DA. Effects of contractile activity on mitochondrial transcription factor A expression in skeletal muscle. J Appl Physiol 2001; 90: 389-396.

13. Lindqvist A, Mei J, Sundler F, Erlanson-Albertsson C. Decreased UCP2 mRNA expression in rat stomach following vagotomy: novel role for UCP2 as free radical scavenger in the stomach? Nutr Neurosci 2004; 7: 217-222.

14. Giorgio V, von Stockum S, Antoniel M, Fabbro A, Fogolari F, Forte M et al. Dimers of mitochondrial ATP synthase form the permeability transition pore. Proc Natl Acad Sci USA 2013; 110: 5887-5892.

15. Machida $\mathrm{K}$, Ohta $Y$, Osada H. Suppression of apoptosis by cyclophilin D via stabilization of hexokinase II mitochondrial binding in cancer cells. J Biol Chem 2006; 281: 14314-14320.

16. Rossignol R, Gilkerson R, Aggeler R, Yamagata K, Remington SJ, Capaldi RA. Energy substrate modulates mitochondrial structure and oxidative capacity in cancer cells. Cancer Res 2004; 64: 985-993.

17. Jho EH, Malbon CC. Galpha12 and Galpha13 mediate differentiation of P19 mouse embryonal carcinoma cells in response to retinoic acid. J Biol Chem 1997; 272: 24461-24467.

18. Zhang J, Nuebel E, Daley GQ, Koehler CM, Teitell MA. Metabolic regulation in pluripotent stem cells during reprogramming and self-renewal. Cell Stem Cell 2012; 11: 589-595.

19. St John JC, Ramalho-Santos J, Gray HL, Petrosko P, Rawe VY, Navara CS et al. The expression of mitochondrial DNA transcription factors during early cardiomyocyte in vitro differentiation from human embryonic stem cells. Cloning Stem Cells 2005; 7: 141-153.

20. Ramalho-Santos J, Varum S, Amaral S, Mota PC, Sousa AP, Amaral A. Mitochondrial functionality in reproduction: from gonads and gametes to embryos and embryonic stem cells. Hum Reprod Update 2009; 15: 553-572.

21. Rera M, Bahadorani S, Cho J, Koehler CL, Ulgherait M, Hur JH et al. Modulation of longevity and tissue homeostasis by the Drosophila PGC-1 homolog. Cell Metab 2011; 14: 623-634.

22. Ye XQ, Li Q, Wang GH, Sun FF, Huang GJ, Bian XW et al. Mitochondrial and energy metabolism-related properties as novel indicators of lung cancer stem cells. Int $\mathrm{J}$ Cancer 2011; 129: 820-831.

23. Chen C, Liu Y, Liu R, Ikenoue T, Guan KL, Zheng P. TSC-mTOR maintains quiescence and function of hematopoietic stem cells by repressing mitochondrial biogenesis and reactive oxygen species. J Exp Med 2008; 205: 2397-2408.

24. Mohyeldin A, Garzon-Muvdi T, Quinones-Hinojosa A. Oxygen in stem cell biology: a critical component of the stem cell niche. Cell Stem Cell 2010; 7: 150-161.

25. Zhang J, Khvorostov I, Hong JS, Oktay Y, Vergnes L, Nuebel E et al. UCP2 regulates energy metabolism and differentiation potential of human pluripotent stem cells. EMBO $J$ 2011; 30: 4860-4873

26. Folmes CD, Nelson TJ, Martinez-Fernandez A, Arrell DK, Lindor JZ, Dzeja PP et al. Somatic oxidative bioenergetics transitions into pluripotency-dependent glycolysis to facilitate nuclear reprogramming. Cell Metab 2011; 14: 264-271. 
27. Ye XQ, Wang GH, Huang GJ, Bian XW, Qian GS, Yu SC. Heterogeneity of mitochondrial membrane potential: a novel tool to isolate and identify cancer stem cells from a tumor mass? Stem Cell Rev 2011; 7: 153-160.

28. Kroemer G, Pouyssegur J. Tumor cell metabolism: cancer's Achilles' heel. Cancer Cell 2008; 13: 472-482.

29. Schieke SM, Ma M, Cao L, McCoy JP Jr, Liu C, Hensel NF et al. Mitochondrial metabolism modulates differentiation and teratoma formation capacity in mouse embryonic stem cells. J Biol Chem 2008; 283: 28506-28512.

30. Ramos-Mejia V, Bueno C, Roldan M, Sanchez L, Ligero G, Menendez $\mathrm{P}$ et al. The adaptation of human embryonic stem cells to different feeder-free culture conditions is accompanied by a mitochondrial response. Stem Cells Dev 2012; 21: $1145-1155$.

31. Armstrong L, Tilgner K, Saretzki G, Atkinson SP, Stojkovic M, Moreno R et al. Human induced pluripotent stem cell lines show stress defense mechanisms and mitochondrial regulation similar to those of human embryonic stem cells. Stem Cells 2010; 28: 661-673.

32. Vander Heiden MG, Locasale JW, Swanson KD, Sharfi H, Heffron GJ, Amador-Noguez D et al. Evidence for an alternative glycolytic pathway in rapidly proliferating cells. Science 2010; 329: 1492-1499

33. Mandal S, Lindgren AG, Srivastava AS, Clark AT, Banerjee U. Mitochondrial function controls proliferation and early differentiation potential of embryonic stem cells. Stem Cells 2011; 29: 486-495

34. Hom JR, Quintanilla RA, Hoffman DL, de Mesy Bentley KL, Molkentin JD, Sheu SS et al. The permeability transition pore controls cardiac mitochondrial maturation and myocyte differentiation. Dev Cell 2011; 21: 469-478.

35. Shakya A, Cooksey R, Cox JE, Wang V, McClain DA, Tantin D. Oct1 loss of function induces a coordinate metabolic shift that opposes tumorigenicity. Nat Cell Biol 2009; 11: 320-327.

36. Tormos KV, Anso E, Hamanaka RB, Eisenbart J, Joseph J, Kalyanaraman B et al. Mitochondrial complex III ROS regulate adipocyte differentiation. Cell Metab 2011; 14: 537-544.

37. Prigione A, Adjaye J. Modulation of mitochondrial biogenesis and bioenergetic metabolism upon in vitro and in vivo differentiation of human ES and iPS cells. Int J Dev Biol 2010; 54 : $1729-1741$.

38. Denton RM. Regulation of mitochondrial dehydrogenases by calcium ions. Biochim Biophys Acta 2009; 1787: 1309-1316.

39. Villalobo A, Lehninger AL. Inhibition of oxidative phosphorylation in ascites tumor mitochondria and cells by intramitochondrial Ca2 +. J Biol Chem 1980; 255: 2457-2464.

40. Porter GA Jr, Makuck RF, Rivkees SA. Reduction in intracellular calcium levels inhibits myoblast differentiation. J Biol Chem 2002; 277: 28942-28947.

41. Hausenloy D, Wynne A, Duchen M, Yellon D. Transient mitochondrial permeability transition pore opening mediates preconditioning-induced protection. Circulation 2004; 109: $1714-1717$

42. Hou T, Zhang X, Xu J, Jian C, Huang Z, Ye T et al. Synergistic triggering of superoxide flashes by mitochondrial $\mathrm{Ca} 2+$ uniport and basal reactive oxygen species elevation. J Biol Chem 2013; 288: 4602-4612.
43. Gao J, Sana R, Calder V, Calonge M, Lee W, Wheeler LA et al. Mitochondrial permeability transition pore in inflammatory apoptosis of human conjunctival epithelial cells and T cells: effect of cyclosporin A. Invest Ophthalmol Vis Sci 2013; 54: 4717-4733.

44. Mathupala SP, Ko YH, Pedersen PL. Hexokinase II: cancer's double-edged sword acting as both facilitator and gatekeeper of malignancy when bound to mitochondria. Oncogene 2006; 25: 4777-4786.

45. Varum S, Rodrigues AS, Moura MB, Momcilovic O, Easley CAt, Ramalho-Santos J et al. Energy metabolism in human pluripotent stem cells and their differentiated counterparts. PLoS One 2011; 6: e20914.

46. Michelakis ED, Webster L, Mackey JR. Dichloroacetate (DCA) as a potential metabolictargeting therapy for cancer. Br J Cancer 2008; 99: 989-994.

47. Morfouace M, Lalier L, Bahut M, Bonnamain V, Naveilhan P, Guette C et al. Comparison of spheroids formed by rat glioma stem cells and neural stem cells reveals differences in glucose metabolism and promising therapeutic applications. J Biol Chem 2012; 287 33664-33674.

48. Dagda RK, Cherra SJ 3rd, Kulich SM, Tandon A, Park D, Chu CT. Loss of PINK1 function promotes mitophagy through effects on oxidative stress and mitochondrial fission. $J$ Biol Chem 2009; 284: 13843-13855.

49. Pendergrass W, Wolf N, Poot M. Efficacy of MitoTracker Green and CMXrosamine to measure changes in mitochondrial membrane potentials in living cells and tissues. Cytometry A 2004; 61: 162-169.

50. Elmore SP, Nishimura Y, Qian T, Herman B, Lemasters JJ. Discrimination of depolarized from polarized mitochondria by confocal fluorescence resonance energy transfer. Arch Biochem Biophys 2004; 422: 145-152.

51. Pereira GC, Branco AF, Matos JA, Pereira SL, Parke D, Perkins EL et al. Mitochondrially targeted effects of berberine [Natural Yellow 18, 5,6-dihydro-9,10dimethoxybenzo(g)-1,3-benzodioxolo(5,6-a) quinolizinium] on K1735-M2 mouse melanoma cells: comparison with direct effects on isolated mitochondrial fractions. J Pharmaco Exp Ther 2007; 323: 636-649.

52. Thundathil J, Filion F, Smith LC. Molecular control of mitochondrial function in preimplantation mouse embryos. Mol Reprod Dev 2005; 71: 405-413.

53. Rasmussen HN, Rasmussen UF. Oxygen solubilities of media used in electrochemical respiration measurements. Anal Biochem 2003; 319: 105-113.

54. Petronilli V, Miotto G, Canton M, Brini M, Colonna R, Bernardi $P$ et al. Transient and long-lasting openings of the mitochondrial permeability transition pore can be monitored directly in intact cells by changes in mitochondrial calcein fluorescence. Biophys $J$ 1999; 76 : 725-734.

55. Bernardi $P$. The mitochondrial permeability transition pore: a mystery solved? Front Physiol 2013; 4: 95.

56. Verma G, Bhatia H, Datta M. JNK1/2 regulates ER-mitochondrial Ca2 + cross-talk during IL-1beta-mediated cell death in RINm5F and human primary beta-cells. Mol Biol Cell 2013 24: 2058-2071.

57. Hoth M, Fanger CM, Lewis RS. Mitochondrial regulation of store-operated calcium signaling in T lymphocytes. J Cell Biol 1997; 137: 633-648.

58. Skehan P, Storeng R, Scudiero D, Monks A, McMahon J, Vistica D et al. New colorimetric cytotoxicity assay for anticancer-drug screening. J Natl Cancer Inst 1990; 82: 1107-1112.

Supplementary Information accompanies this paper on Cell Death and Differentiation website (http://www.nature.com/cdd) 